\title{
ASSESSMENT OF THE EFFICIENCY OF SPANISH FOOTBALL TEAMS THROUGH PROFILING
}

\author{
Manuel Espitia-Escuer \\ Lucía Isabel García-Cebrián* \\ Universidad de Zaragoza
}

*Corresponding author:

Lucía Isabel García-Cebrián

Facultad de Economía y Empresa

Gran Vía, 2

50.005 Zaragoza (Spain)

Phone number: 34976762712

e-mail: lgarcia@unizar.es

This research was supported by project grant ECO2016-77843-P (AEI/FEDER, UE) and by the COMPETE S52_17R regional government research group. 


\section{Abstract}

The aim of this paper is to assess the efficiency of Spanish football teams that participated in the Spanish First Division between 2011 and 2016. We started by specifying the production function of football teams using the production process as a basis. Considering all the moves that can be made during a match, ordering them in the logical sequence that usually links them together and considering ball possession and non-possession as different phases lead to disaggregating the match into eight subdivisions whose efficiency is calculated using the data envelopment analysis (DEA) variant known as profiling. The representative input and output variables considered in these eight subdivisions are moves made during the matches. However, the actions football teams perform, irrespective of their type, are not the result of a standardised procedure. This has two consequences on the number of moves in the field of play: firstly, a minimal variation in playing conditions (both the team's and its opponent's) can alter the number; and, secondly, it is very difficult to control and arrive at a figure possibly established in advance. Since these circumstances can be interpreted as data imprecision, one of the stochastic DEA proposals has also been used in this paper as a calculation tool to verify the robustness of the results.

The results show the subdivisions in which the use of moves can be improved to increase the number of actions in the next stage. This knowledge could provide guidance for technical personnel for their training sessions. 


\section{INTRODUCTION}

Professional football clubs form an economic sector with some singularities that stem especially from the regulation the associated entity applies: teams differ due to the game style they play; the cost of their resources, fundamentally players, is not the same for them all; the financial results are not the only criterion to remain in competitions, since other socially relevant criteria are considered; and so on. Consequently, this sector does not fulfil three assumptions of the perfect competition model: companies in a sector adopt the same technology; productive resources are acquired at the same cost; and the absence of exit barriers. In short, these facts prevent them from being considered as an example of a competitive market as understood within the framework of the economic theory.

Since this is not a competitive sector, results will not be those anticipated by the perfect competition model either and, specifically, we can expect differences in the efficient use of resources among football teams participating in the same competition. As in any other organisation, the final output depends on efficient use of resources and their initial provision. In this study we analyse the relationship between efficiency and results in such a way that if we observe that the teams in the top positions are inefficient, their sporting results can be attributed exclusively to the initial provision of resources. However, all inefficient teams can improve their sporting results by increasing their efficiency in the subdivisions where this inefficiency is present. If all the teams were deemed efficient, the number of goals each team scores would only depend on their initial provision of resources. If this situation occurred, sporting success would lie with the team with the highest number of initial resources.

It follows from the above that the professional football sector is not competitive; however, this statement is made on the basis of economic theory's interpretation of the term competition. Without this clarification, it would be strange for a sector whose activity concerns participating in championships, in which the most important aspect is sporting success and winning matches played against an opponent, to be classified as not competitive. That is why we differentiate between competition (economic term) and rivalry on the field of play (sports term). Output in team sport competitions is based on the regulating mechanism, and sporting success does not only depend on the team, but also on the opponent's performance. However, this fact is not exclusive to professional football, since production volume in the manufacturing sector does not usually tally with sales due to external influences that include companies' market competitors, which may attract customers 
depending on the strategy they adopt. Therefore, the action of rival teams in the sport sector could be likened to the influence of the environment, using economics terminology.

This study calculates the efficiency of Spanish football teams that participated in the Spanish First Division between 2011 and 2016. The aim is to analyse the use of production resources to arrive at actions that could improve sporting results. Since the perfect competition model anticipates differences in the efficiency of football teams, learning about it makes sense. In this study we will consider the economics and management science of organisations to describe the production process of sports teams, select the calculation tool used and make recommendations.

The tool used in this paper is the data envelopment analysis (DEA). This method has been widely used in studies focused on the sport sector because of its advantages: it does not need a mathematical specification of the production function and it can calculate efficiency for multi-input and multi-output organisations. DEA results are also easy to convey to organisation managers, which is in line with the economics approach adopted in this study. Nevertheless, this paper presents three new essential aspects: variables taken as representative of the production process of football teams and the relationships between them; the original DEA variant used to conduct the analysis; and the union of this variant with the stochastic DEA.

A DEA requires a precise definition of the process under study and representative variables of resources and products. With the aim of justifying the variables considered as representative of resources and products when applying the DEA in this paper, this study uses a football match as the production process and presents the series of stages in which moves are gradually transformed into the final product.

Network DEA is the modification of the original DEA normally used to calculate the efficiency of organisations during a multi-stage production process. However, after reviewing the literature of the network DEA and the solutions it proposes, we found that they are not suitable for the production structure type this study concerns. Therefore, the variant used in the DEA analysis to conduct the analyses and obtain results consistent with the proposed model is the profiling suggested by Tofallis (1996 and 1997).

Despite adopting a management science approach to interpret efficiency, it should be noted that the chosen calculation tool does not use statistical inference and any error in the basic input data will influence the results; therefore, calculations using stochastic DEA will also be 
presented. According to Olesen and Petersen (2016), a management science approach and a statistical or econometric approach can be found in stochastic DEA. The former focuses on incorporating measurement error in the specification of the reference technology, for example substituting input and output observations for the specific input and output distributions of every organisation in the studied sample. In contrast, the latter emphasises the axiomatic approach: the data are considered a sample of a larger population and a consistent estimator of the true frontier is sought. The implications of this second approach are not always easy for decision-makers to interpret, which is why in this paper we have used a management science perspective in the stochastic DEA.

The structure of this paper is as follows. In the second section, we use the match as the production process of football teams, describe the actions or moves that can take place and, based on the relationships between them, we specify the production function of a football team divided into stages. In the following section, we explain the efficiency calculation method. Given that it has been recognised that the production process is divided into phases, we show analysis proposals using the profiling method, which applies to both the original DEA and the stochastic DEA approach in this paper. Next, we show the results we obtained and end our study with our conclusions.

\section{REPRESENTATIVE VARIABLES OF THE PRODUCTION FUNCTION IN FOOTBALL TEAMS}

In the context of professional football teams, the DEA has often been used in efficiency calculations; however, studies are not unanimous about the variables they deem representative of inputs and outputs. Although there is some agreement on the fact that the product of football teams should be a representative variable of their sporting results, there are studies where it is combined with others (Haas, (2003 a); Haas, (2003 b); and Haas, Kocher and Sutter (2004)) or it is a variable related to the economic result (Guzmán, 2006). Concerning variables representing resources, previous studies use expense items, and Haas (2003 a) adds the population of the city where the team is established. Studies by EspitiaEscuer and García-Cebrián (2004), for example, use attacking moves performed in the field.

As there is a variety of alternatives for considering resources and products, we can base our examination of the organisational units the efficiency calculation is applied to on general recommendations made by several authors outside the sport sector. 
The study by Farrell (1957) can be considered the pioneer in frontier methods of efficiency calculation. This study takes the graphic representation of the isoquant as a basis so that the variables it considers as inputs would be the production resources that transform into the final products. Triantis (2004) also insists that the efficiency calculation must be applied to production processes in which the resources become final products, and Cook, Tone and Zhu (2014) emphasise the importance of knowing which transformation process is to have its efficiency assessed. Golany and Roll (1989) propose a series of ideas to correctly distinguish the representative variables of the inputs of variables that would explain the differences detected in efficiency values.

Production processes have a technical basis (Triantis, 2004) and, according to Liu, Lu, Lu and Lin (2013), they can be interpreted as the current 'black boxes' whose internal structures are unknown. Consequently, to apply the efficiency calculation to every process, it is advisable to consult experts in the technology used in the process to be analysed, since they have the knowledge to determine which inputs are used and which outputs are obtained.

Based on the ideas of Schofield (1988), Carmichael and Thomas (1995) and Carmichael, Thomas and Ward (2000), the production function of team sports can be divided into two phases: in the first, the skills of the players and the coach become actions or moves to be performed during the match, and in the second phase, which is the match, these moves transform into the sporting result. This study focuses on the match and this will be the process whose efficiency we calculate. Consequently, the resources considered for the efficiency calculation of the football teams will be the activities that occur during the match.

Menéndez, Bello-Orgaz and Camacho (2013) provide the following list of moves in a football match: clearances, fouls, passes, goal shots, runs and distance covered. For the goalkeeper they consider recovered balls, clearances, passes, balls lost and saves. Actions analysed in documents for football coaches are control, running with the ball, dribbling and goal shots while a player possesses the ball, passing the ball to another player in his team, challenges, interceptions, tackles and fouls to gain possession of the ball when his opponent has it and the goalkeeper's actions (Cantarero, 1995).

In a 'black-box' production process perspective, all the above-mentioned variables would be taken jointly as resources to obtain the sporting output. Nevertheless, again tapping into expert knowledge, the types of moves mentioned do not contribute in the same way to obtaining the product; in other words, they are not substitutable resources. This means we 
need to explore the relationships between them to arrive at a more precise description of the production process. Two rival teams oppose each other during the match and the development of the game each team plays, which would be equivalent to the production process, reflects this interaction. The variables that more immediately show this interrelation between the opposing teams are possession and non-possession times.

The definition of possession can be found in Pollard and Reep (1997), Jones, James and Mellalieu (2004) and in Tenga, Holme, Ronglan and Bahr (2010 a), Tenga, Holme, Ronglan and Bahr (2010 b). In all these studies, the team's possession is deemed to commence when the ball reaches one of its players by any means except a pass from a player in the same team. In turn, the player receiving the ball must have control of it to influence its direction. Possession ends when the team scores a goal, when it commits an offence or when the ball is obtained by a player from the rival team.

From a technical point of view, it is during possession time when a team has the possibility to make moves leading to a goal. In contrast, when a team does not possess the ball, all the actions they perform are aimed at recovering it. In fact, Gómez-López and Álvaro-Alcalde (2002) liken possession time to performing attacking moves, whereas defensive moves are made during non-possession time. Game objectives also vary depending on circumstances: the aim while possessing the ball is to keep control of it, advance towards the opposite team's goal and create a shot that ends in a goal; and during the defensive phase, the team tries to recover the ball and prevent its rival from scoring any goals.

Consequently, we could consider possession time as a resource. ${ }^{1}$ However, we have not adopted this focus in this paper, since the passing of time, or the time taken to perform an activity, is not considered an input in the meaning given to it by economic theory. It is the relevant variable for assessing speed or output per minute, but that is not the meaning of efficiency. Given that a team's objective when it has possession differs from its perspective when it loses the ball, we will propose a particular specification of the production function for each case.

\footnotetext{
${ }^{1}$ Possession has been introduced in various ways in research. Tenga, Holme, Ronglan and Bahr (2010 a), Tenga, Holme, Ronglan and Bahr (2010 b), and Pollard and Reep (1997) take possession as an analysis unit. Hughes and Bartlett (2002) and Lago and Martin (2007) consider it as a result indicator and Jones, James and Mellalieu (2004) as a variable explaining sporting success. For Espitia-Escuer and García-Cebrián (2004) possession minutes in favour are a resource in calculating the efficiency of football teams.
} 
The purpose of possession is to score a goal. To do that, one of the team's players must shoot at the opposing team's goal. This shot arises from an assist from another team player, and this player will also have received the ball from passes from other players. These passes will have begun once the team recovered the ball and possession by the analysed team began. This would be the typical series of moves from when possession begins to when a goal is eventually scored. However, other circumstances exist to the game played between players on the same team that lead to the possibility of scoring a goal and which are essentially due to the rival team's actions, penalties they commit, corners they give away, fouls they commit deemed a direct free kick or an indirect free kick, which all require the contribution of another member of the team to take the kick and eventually score a goal.

Three additional actions that teams perform when they possess the ball are mentioned in football technical manuals for coaches: running with the ball, control and dribbling. These are basically the actions every player performs when they possess the ball with the aim of not losing it and being able to pass it to another member of their team or take a shot at goal. Only one player is involved in these moves, whereas two players are involved in the aboveconsidered moves and they form the evidence of joint activity performed by football team members. Running with the ball, control and dribbling are not actions directly related to goals as their purpose is to avoid losing the ball. In other words, they form part of a series of activities that must be performed in a certain order to score a goal. But the team needs to keep possession of the ball to interact with the other team members in passes, assists and shots. Therefore, we can consider that running with the ball, control and dribbling are the inputs of a process whose purpose is to avoid losing the ball and they are transformed into passes, assists and shots at the opponent's goal.

Consequently, we can consider that there are two processes involved in the ball possession process and they could be represented graphically as follows:

Graph 1. Sequence of moves during ball possession

Source: Own

We should clarify that once a team gains the ball, they can start to pass it to each other and although the relationship between passes and assists has been shown in the above graph as if 
the former could only transform into the latter, in actual fact the representative rectangle of passes would contain all those made whether they lead to other passes or assists.

In addition, the purpose of non-possession time is to take possession of the ball and prevent the other team from scoring a goal. Consequently, the outputs would be clearances and recovered balls. The actions that players in the team without possession perform for that purpose are challenges, interceptions and tackles. Throw-ins resulting from the rival team's actions and saves made by the goalkeeper of one's own team can also result in recovered balls. Consequently, the production process of non-possession of the ball could be represented graphically as follows:

Graph 2. Sequence of moves during non-possession of the ball

Source: Own

The relationship between the representative input and output variables in this process of nonpossession of the ball is similar to the relationship found in running with the ball, control and dribbling: challenges, interception and tackles, throw-ins and saves are actions that every player can make individually to gain the ball or prevent opponents from scoring. However, there is no relationship of technological precedence between them indicating the order in which they should be executed.

Lastly, we should focus on the goalkeeper's production process. His actions are aimed at preventing the rival team from scoring a goal resulting from either a shot at goal by one of their players or a penalty kick. Therefore, outputs generated by the goalkeeper's actions are saves (which are also inputs in the possession process) and saved penalties. This process could be represented graphically as follows:

Graph 3. Sequence of the goalkeeper's moves 
Taking ball possession and non-possession times as a basis to seek representative input and output variables of the production process of football teams has prevented the need to differentiate between attacking and defensive moves, as Dobson and Goddard (2010) do, for example. Similarly, using the moves performed during the match as the input rather than the times solves the problem of finding which is the best variable to assess the effectiveness of possession considered by Pollard and Reep (1997).

Furthermore, specifying the production process, which has been presented here, involves two peculiarities that have already been considered in the literature. Firstly, a sequential process that can also be found in Blass (1992) and in Deli (2012) applied to baseball and in Carmichael, Thomas and Ward (2001) to football. In the latter study, they estimate some recursive equations that are based on the following outline:

- The difference between scored and conceded goals is turned into points.

- Conceded goals depend on failures in defence and the rival's attacking moves.

- Scored goals depend on shots.

- Ball possession turns into shots.

Secondly, the inputs considered are not traditional production resources (capital, work and materials) but activities. This is also the case in Lovell, Walters and Wood (1994) in a study focused on the education sector and in Chilingerian and Sherman (2004) on medical care.

In all the processes detailed in our study, the number of actions considered resources that are required to obtain an action considered an output is not fixed or known beforehand. This uncertainty of whether a certain move will end in the expected, beneficial result for the team involved in it is precisely one of football's attractions as a spectacle. Consequently, given that we do not know in advance how a move taken as an input in a process will be end, it makes sense to calculate the efficiency that measures and analyses how available resources are used. In short, the assessment of efficiency in this study will evaluate how a certain move or set of moves is used to transform into others. However, the calculation of the efficiency of football teams is not limited to knowing which are efficient, since the causes of the inefficiencies are identified in a later stage in the analysis. As in any organisation, inefficiency in the case in question may be due to defective performance of the tasks the resources are entrusted with, essentially due to players' lack of skills.

It could also be due to an additional cause related to the general tactics the coach imposes. The aim in all the detailed processes is to represent the usual relationship of transforming the 
moves football teams make by paying attention to their essence. However, a coach can decide to change the sequence of moves because he believes that playing differently would be more favourable due to his team's characteristics. In this case, we can anticipate that this team will have a low efficiency value in the transformation into output. This can be accompanied by a higher efficiency in the process whose output is the move the coach decides is the result of the above-mentioned original action. However, we should always analyse whether changing from the standard game leads to better sporting results beyond its impact on efficiency in one of the stages a football match can be divided into.

However, given the interrelation between the two rival teams in the field of play, one team's inefficiency might also be attributable to their rival's actions in preventing their actions turning into the desired output. When a team makes a move, but it does not end in the one that follows it based on the usual design of production processes, this might be due to the team's own lack of expertise or the skill of the opposing team in gaining possession of the ball. Although only the first cause would be attributable to inefficiency, in principle, the DEA calculation of efficiency would not distinguish between them. The rival's influence would be likened to the influence of the environment on a manufacturing company and the DEA advises that the environment of organisations forming the sample for an efficiency calculation should be as homogenous as possible. This difficulty in correctly interpreting the results is lessened by calculating efficiency based on data for every complete season. Consequently, the influence that rivals may exert in ending moves is experienced by all the teams when playing against each other at home and away in the Spanish First Division.

A rival's actions also influence the team's own actions and the final sporting result: the difference between scored and conceded goals determines who the winner is. The winner is not the team that obtains the number of goals established in advance, but the one that scores more goals than its rival. Furthermore, if the observation unit is not just one match, but a championship, each match's goal difference is the basis of a point system that dilutes information on the results of the teams match by match. In short, the fact that the number of goals is related indirectly to the points that provide the final classification can be interpreted in economic terms as the goals being the manufactured product and the points, which depend on the environment (rival's performance and goals), the sales made. Consequently, the ball possession process considered in this study focuses on obtaining goals and this is the variable that measures the final output. 


\section{DEA METHOD}

Lack of knowledge of the production possibility set results in needing to calculate the efficiency of actual organisations using a reference technology that, according to Olesen and Petersen (2016), reveals both the observed data and the axioms characterising the production possibility set. For these authors, the purpose of the DEA is to measure relative efficiency and to order a sample of organisations (decision-making units or DMUs) as homogenously as possible in accordance with this criterion. Based on the observed data, every DMU is represented by a vector with the used resource quantities that have made it possible to produce an output vector. Concerning the axiomatic structure, in the DEA it is summarised in four assumptions required from the production possibility set (Johnson, 2017) — convexity, monotonicity, inclusion and minimum extrapolation. In short, the DEA is a deterministic tool, which, according to Johnson (2017) requires the model to be exhaustively specified and the data to be measured correctly for the efficiency estimate to be consistent. However, for this author, calculating efficiency with the DEA has the advantages of simplicity, since it uses linear programming, and ease of use in multiple-input and multiple-output production cases. For Olesen and Petersen (2016) an additional DEA advantage is the non-parametric estimate (with no functional form and without assuming a distribution of inefficiency) of the reference technology, since it is only based on the abovementioned production theory axioms. Furthermore, according to the same authors, DEA calculations obtain the efficiency ratios of the organisations forming the sample and the reference organisations of those considered inefficient. Consequently, informing decision-making managers in organisations of the results is very simple, thus leading to the DEA being implemented in the area of management science.

The use of the DEA as a calculation tool comprises solving the following linear programming problem for every one of the organisations in the sample if an input orientation is adopted and constant returns to scale are considered:

Min. $\theta_{0}$

$$
\begin{array}{lll}
\text { s.t. } & \sum_{\mathrm{j}=1}^{\mathrm{n}} \mathrm{x}_{\mathrm{ij}} \lambda_{\mathrm{j}} \leq \theta \mathrm{x}_{\mathrm{i} 0} & \mathrm{i}=1,2, \ldots, \mathrm{m} \text { (inputs) } \\
& \sum_{\mathrm{j}=1}^{\mathrm{n}} \mathrm{y}_{\mathrm{rj}} \lambda_{\mathrm{j}} \geq \mathrm{y}_{\mathrm{r} 0} & \mathrm{r}=1,2, \ldots, \mathrm{s} \text { (outputs) } \\
& \lambda_{\mathrm{j}} \geq 0 & \mathrm{j}=1,2, \ldots, \mathrm{n} \text { (DMUs) }
\end{array}
$$

The values $\theta_{0}$ and $\lambda_{j}$ are the results of the problem. The former is the efficiency ratio, which is interpreted as follows: DMUs for which it has a value equal to the unit are considered 
efficient since their output quantities cannot be obtained with less consumption of inputs, while DMUs for which it has a value below one are inefficient and represent the percentage to which resource consumption should be reduced to obtain the same product quantity, but being efficient, in other words, with no waste.

If output orientation is adopted while maintaining the hypothesis of constant returns to scale, the problem to solve is as follows:

$$
\begin{array}{lll}
\text { Max. } & \mu_{0} & \\
\text { s.t. } & \sum_{\mathrm{j}=1}^{\mathrm{n}} \mathrm{x}_{\mathrm{ij}} \lambda_{\mathrm{j}} \leq \mathrm{x}_{\mathrm{i} 0} & \mathrm{i}=1,2, \ldots, \mathrm{m} \text { (inputs) } \\
& \sum_{\mathrm{j}=1}^{\mathrm{n}} \mathrm{y}_{\mathrm{rj}} \lambda_{\mathrm{j}} \geq \mu_{0} \mathrm{y}_{\mathrm{r} 0} & \mathrm{r}=1,2, \ldots, \mathrm{s} \text { (outputs) } \\
& \lambda_{\mathrm{j}} \geq 0 & \mathrm{j}=1,2, \ldots, \mathrm{n} \text { (DMUs) }
\end{array}
$$

In this case, the efficiency ratio $\mu_{0}$ takes values equal to or greater than the unit and indicates the proportion that the output amounts obtained by the DMUs could reach in the sample based on current resource consumption. Therefore, DMUs with a ratio equal to one are efficient.

In the original DEA version, according to Liu, Lu, Lu and Lin (2013), the internal structure of organisations can be considered a type of 'black box' whose stages or subprocesses are not considered. Given that this study is based on a detailed structure of the tasks that football teams must perform to score a goal, we will review the DEA literature that deals with the internal structure of organisations whose efficiency is calculated, specifically network DEA and profiling. We will also present a review of the literature on stochastic DEA because the recommendations stemming from the results of the original DEA for inefficient teams to stop being inefficient cannot be applied as accurately and precisely as the method entails, since the number of moves made during matches (the variables considered in this study as representative of resources and products) is difficult to control because a football match is not a standardised production process.

\subsection{Network DEA ${ }^{2}$}

Organisations can be highly complex and their division into subunits or subprocesses can be classified into three structures according to Castelli, Pesenti and Ukovich (2010):

\footnotetext{
${ }^{2}$ Two exhaustive reviews of the literature on network DEA can be found in Castelli, Pesenti and Ukovich (2010) and in Kao (2014).
} 
$\checkmark$ Shared flow models: to perform their tasks, subunits require inputs exclusively dedicated to each of them, but there are also resources shared by two or more. Similarly, some organisation outputs are obtained exclusively by one subunit, but others come from two or more. To outline the linear programming problem that calculates efficiency in these cases we need to know the proportion of shared resources and products, which, respectively, every subunit uses and produces.

$\checkmark$ Multilevel models: these include cases in which the organisation uses or obtains inputs and outputs in addition to those of their subunits.

$\checkmark$ Network models: these occur when there are flows of goods between the subunits. In these models part of the production of some subunits can be used as inputs by others and there is then no independence between them.

According to $\mathrm{Liu}, \mathrm{Lu}$ and $\mathrm{Lu}$ (2016), network DEA is one of the advanced research lines in the DEA field. In this study, we will review the structures that can be found in the processes broken down into stages according to Kao (2014), for whom there are basically four: basic two-stage structure; general two-stage structure; series structure; and parallel structure. ${ }^{3}$ The models included in the basic two-stage structure consider that the organisation's production process is divided into two phases. The products of the first phase, intermediate measures, are all the resources the second phase uses to perform its activity. The general two-stage structure is found in processes divided into two phases, but part of the production of the first phase is not resources consumed by the second, which in turn uses external inputs. Although Kao (2014) also presents a parallel structure, it cannot be considered an example of the network model in the terminology of Castelli, Pesenti and Ukovich (2010), since all the subprocesses it is divided into are independent, even though they can share resources.

The structure of the production function for football teams established in this study does not correspond exactly to any of the above. In the process for non-possession, recovered balls can come from resources used exclusively for that purpose (throw-ins and saves) and also from resources shared with clearances (challenges, interception and tackles). However, it cannot conform to a shared flow model because we do not know which part of the shared resources serves to produce each output. For actions performed during possession time, as more than two phases have been proposed, it does not conform to the two-stage structure, either the basic structure (some incorporated resources do not stem from the previous phase, such as

\footnotetext{
${ }^{3}$ A review of various structures for two-stage and multilevel processes can also be found in Despotis, Sotiros and Koronakos (2016).
} 
fouls, corners and penalties) or the general structure. Given that it comprises more than two phases, it could correspond to the series structures, but there are no shared resources. In the case of football, the passes resource includes both passes with assists and passes that become other passes; in short, it is a variable whose value contains both resources from the first move after taking possession of the ball and intermediate products that do not become assists.

Another difference between the case in question and the aforementioned articles lies in the calculations. Given that the representative structure of the production function in football contains a series of moves that can, in a standard format, lead to a goal, ball recovery or prevent one's opponent from scoring, calculating the efficiency of each stage can highlight differences in the game teams play. Therefore, understanding the efficiency of each transformation phase rather than the efficiency of the entire organisation is of interest.

Lastly, shared input issues are not relevant in the case of the production function of football teams that concerns us here. Given that the starting point is the usual series of moves, if we consider the quantity of every shared action ending in every output, the ratio would always be one-to-one and the moves that do not end in the action for which they were designed would not be shown in the data. This would not enable us to analyse efficiency differences. Remaining unaware of the proportion in which every action should be distributed among the outputs sharing it would not be useful since, due to the rival team's influence, we cannot guarantee when applying the numerical results that all the actions taken in matches effectively manage to obtain the action for which they were conceived.

There is abundant literature on applying the network DEA in the sports sector. Given that the examples and analysed focuses are diverse, a brief review can be useful to determine whether any of them are similar to the approach in our study.

Research by Lei, Li, Xie and Liang (2015) and Li, Lei, Dai and Liang (2015) study the efficiency of countries in winning Olympic medals. The former assumes a parallel structure with shared resources and provides the means to calculate the efficiency for the whole and the optimal distribution proportion based on proposals by Kao (2012). Li, Lei, Dai and Liang (2015) establish a basic two-stage structure and calculate efficiency based on the centralised model proposed by Kao and Hwang (2008) in which the efficiency of the whole is the product of the efficiency in each stage. Given the aim of these two studies, the type of resources they focus on and the production structure they lead to, they are quite dissimilar to our own research. 
Although studies based on a basic two-stage structure do not coincide with the approach in this paper, they are present in the literature and are worth mentioning. Kern, Schwarzmann and Wiedenegger (2012) focus on English football and calculate both the efficiency of every stage independently and the efficiency of the whole without considering intermediate inputs. Another difference between our work and theirs is that they do not view moves as a production resource. A basic two-stage structure and moves incorporated into inputs are found in the works by Yang, Lin and Chen (2014) and Moreno and Lozano (2015). Both take the NBA as their study sample. The former calculates the efficiency of the whole as the weighted sum of the efficiency in every stage as Chen and Zhu (2004) do, and the latter calculates the efficiency ratio for the entire team to enter it in the calculation of a Malmquist index. Sexton and Lewis (2003) also represent the production function of baseball using the basic two-stage structure. Besides the efficiency of the whole as if intermediate inputs did not exist, they calculate the efficiency of every stage and allocate the efficiency of the second stage as the team's efficiency if the first stage was efficient.

Other studies use more complex structures but do not present the peculiarities of the structure that we want to analyse here. García-Sánchez (2007) focuses on Spanish football, establishes a three-stage structure (parallel attacking and defending actions, creating points and social effectiveness) and takes the efficiency ratio of the previous stage as the input for the next. Moreno and Lozano (2014) study the NBA and also consider a three-stage process (the budget becomes moves, the moves points and the points victories). Villa and Lozano (2016) propose a parallel structure of defensive and attacking moves to obtain goals to describe the production process of Spanish football teams. In this parallel structure, there are no shared resources or products and they calculate the efficiency of the teams in home matches, away matches and for the team as a whole. Lewis, Lock and Sexton (2009) study baseball with a structure in which defensive and attacking actions are parallel, but their products serve as resources for the integration activity, whose output is won matches. They calculate defensive and attacking efficiency and integration separately and they allocate the efficiency the integration activity would obtain if the previous stages had been efficient as the team's efficiency in a similar way as Sexton and Lewis (2003) do.

The reason why the above-mentioned studies differ from the structure presented here might be because we consider actions or moves as production resources in our research and the structure we propose explains in detail the technological precedence relation between them. In other words, the production function analysed in this paper is a sequence of tasks to be 
performed in three different processes (scoring a goal, gaining possession of the ball or preventing the opponent's victory), while all the moves in the aforementioned studies were taken in the same stage in the sequence. Our study aims to further open the 'black box' of the production process of football teams.

\subsection{Profiling}

In papers by Tofallis (1996 and 1997) he proposes calculating efficiency using DEA for each of the resources separately (profiling). Although the purpose of his research was not to solve the efficiency calculation of organisations whose production process can be divided into stages, the proposals he makes can be useful and can be applied when we open the 'black box' that has usually represented production processes.

Although Tofallis (1996) uses DEA as a multi-criteria decision-making tool (he calls variables for which it is beneficial to have a higher value 'outputs', variables for which the opposite is true 'inputs' and he interprets the efficiency ratio resulting from the linear programming problem as a desirability ratio) and Tofallis (1997) proposes calculating the efficiency of production processes, in both studies the author starts from the duality of the problem (1), which is posed as follows:

$$
\begin{array}{lll}
\text { Max. } & \sum_{\mathrm{r}=1}^{\mathrm{s}} \mu_{\mathrm{r}} \mathrm{y}_{\mathrm{r} 0} & \\
\text { s.a. } & \sum_{\mathrm{r}=1}^{\mathrm{s}} \mu_{\mathrm{r}} \mathrm{y}_{\mathrm{rj}}-\sum_{\mathrm{i}=1}^{\mathrm{m}} v_{\mathrm{i}} \mathrm{x}_{\mathrm{ij}} \leq 0 & \mathrm{i}=1,2, \ldots, \mathrm{m} \text { (inputs) } \\
& \sum_{\mathrm{i}=1}^{\mathrm{m}} v_{\mathrm{i}} \mathrm{x}_{\mathrm{i} 0}=1 & \mathrm{r}=1,2, \ldots, \mathrm{s} \text { (outputs) } \\
& \mu_{\mathrm{r}}, v_{\mathrm{i}} \geq 0 & \mathrm{j}=1,2, \ldots, \mathrm{n} \text { (DMUs) }
\end{array}
$$

The fundamental flaw the author sees in the DEA is that it is weak at discriminating, since when the number of DMUs in the sample is low compared with the number of inputs and outputs, many organisations seem efficient. According to Tofallis (1996 and 1997), the solutions proposed in the literature have included more organisations in the study sample, the calculation of cross-efficiency (Doyle and Green (1994)) or added restrictions based on previous opinions or arbitrary limits on the $\mu_{\mathrm{r}}$ and $v_{\mathrm{i}}$ coefficients of the problem (3). This author also identifies additional problems in the DEA. Tofallis (1996) explains that the optimal values for the $\mu_{\mathrm{r}}$ and $v_{\mathrm{i}}$ weightings obtained from the problem solution (3) can be quite unrealistic and even make no sense (which is why other authors have proposed adding 
restrictions to their values). In Tofallis (1997) he recognises that the original version of the DEA proposes reducing the consumption of all their resources by the same percentage as a solution for organisations detected as inefficient. This recommendation is not completely valid since, after reducing the consumed amount of resources by this percentage, some resources might need to be reduced even further for some inputs so that the organisation in question can be located on the isoquant. ${ }^{4}$ In the literature, solutions have been proposed for the problems raised by Tofallis (1996 and 1997). The Russell index (Färe and Lovell, (1978)) can be calculated or the slack-based DEA (Tone, 2001) used to deal with slacks appropriately; and Andersen and Petersen (1993) propose calculating super-efficiency to increase discrimination, at least among efficient organisations.

Nevertheless, the solution Tofallis (1996 and 1997) proposes is based on the fact that the original version of the DEA recognises (almost always implicitly) that production resources are substitutes and that they all contribute to producing all the outputs. Given that this is not the case, Tofallis (1996 and 1997) establishes the calculation of efficiency separately so that each resource is used only to produce the outputs it has a relationship with. Only if there is a group of substitutable resources to produce a product should efficiency be calculated for all of them together. With this solution, we can avoid incorporating additional restrictions and value judgements, which Tofallis (1997) is not in favour of.

The production function proposed as representative of the activity of football teams during a match considers that not all the actions or moves made in a game help to score a goal. Therefore, we recognise, as Tofallis (1996 and 1997) does, that these are not substitutable resources and the original version of the DEA cannot be applied. Based on this idea, we have turned to the information provided by experts on the subject to discover the relationship between moves observed during a match and we have arrived at different situations: a sequence of actions while the team possesses the ball, shared resources in the event of nonpossession, a move (passes) that leads to moves of the same and other types, and so on. Given that this complexity prevents us from applying the network DEA, we instead turn to profiling as a suitable tool. The results obtained from applying the method Tofallis (1996 and 1997) proposes are summarised in a profile, in other words, an efficiency ratio for every subdivision in the organisation in question providing knowledge of the strengths and weaknesses of every

\footnotetext{
${ }^{4}$ The difference between the minimum quantity of resources to be used and the quantity resulting from the radial reduction indicated by the efficiency ratio calculated using the DEA is called slack. An inefficient organisation can also have slack in outputs and in this case, it would be the quantities the product should increase by to be located on the isoquant.
} 
DMU or on the sources of inefficiency and its magnitude, which amounts to the same. The recommendation Tofallis (1996 and 1997) makes of calculating the efficiency ratio for every input (or group of them if they are really substitutes) results in knowledge of the efficiency of the DMUs forming the sample by area, which do not necessarily correspond to stages in the production process. ${ }^{5}$ Normally no organisation is efficient in all the subdivisions; therefore, the result we obtain represents best practices in every one of the subdivisions for which efficiency has been calculated.

As the original version of the DEA provides only one ratio for every DMU, Tofallis (1996) suggests using value judgements, which, for example, allocate weightings or minimum values to be obtained for the efficiency ratios in every subdivision and Tofallis (1997) suggests allocating the highest value of the ratios forming the profile to every DMU.

\subsection{Stochastic DEA}

In this paper, the DEA has been chosen as an efficiency calculation tool due to its advantages. However, although the football teams in the study sample have participated in the same championship and have all played against each other, they may not be as homogeneous as the application of this tool requires. Furthermore, in this research, we measure the efficiency of the football teams' activity on the field of play, which can be considered a labour-intensive production process. In this case, as in any other type of organisation, the efficiency calculation includes the isoquant estimate. However, fulfilling the general recommendation for an inefficient team to become efficient by proportionally and exactly increasing the number of moves made during matches (the output variables considered in this study) to $\mu_{0}$ is not easy.

The DEA's statistics-based characteristics cited in Olesen and Petersen (2016) have to be added to the above. Firstly, the DEA does not consider measurement errors, specification errors in the model or sample noise, nor does it suggest any axiom for deviating inefficient DMUs from the frontier. Secondly, any set of observed DMUs is not interpreted as the result of a sampling process from a larger population.

In short, despite its advantages, the DEA presents limitations for evaluating football team inefficiency and these limitations arise from both the method's deterministic aspects and the

\footnotetext{
${ }^{5}$ In fact, Tofallis (1997) takes a sample comprising airline companies as an example and he calculates efficiency in the use of every input separately (capacity in tonnes-km, operating costs and non-flight-related assets) to obtain the companies' two outputs (passengers-km and revenue not stemming from passengers).
} 
characteristics of the sector studied in this paper. Consequently, we should consider using another calculation method, such as the stochastic frontier analysis (SFA), which for Olesen and Petersen (2016) is an alternative approach to the DEA for measuring efficiency. For these authors, the SFA is based on a parametric specification of the production function and it uses regression techniques and establishes assumptions on the distribution of noise and inefficiency to seek the consistent estimator of the true frontier. ${ }^{6}$ They also state that, while the DEA was developed in the field of management science, the SFA is part of a statistical or econometric tradition that is supported by an axiomatic base and considers that the observed data are a sample of an underlying population and subject to specification errors and other sources of noise. In conclusion, the SFA overcomes all the disadvantages that arise in the DEA from its deterministic and non-parametric nature.

The advantages and disadvantages of DEA and SFA are also compared in the study by Ondrich and Ruggiero (2001). They again state that the DEA assumes that all deviations from the production frontier represent inefficiency, that it does not allow measurement errors or other statistical noises, and they add that their critics argue that the resulting efficiency ratios are contaminated. Concerning the SFA, these authors emphasise that the specification of the production function in this model introduces an error divided into two parts: inefficiency and measurement errors. However, they demonstrate in their research that SFA models cannot generate a reliable estimate of absolute measurements of inefficiency and so they conclude that stochastic models represent no advantages over deterministic models.

Nevertheless, there is a third way of measuring efficiency, namely stochastic DEA, defined in the research by Banker, Kotarac and Neralic (2015) as: "a part of DEA methodology in which stochastic models based on the possibility of random variations in input-output data are studied" (p. 142). Similarly, for Olesen and Petersen (2016) the stochastic DEA is: "an efficiency analysis using non-parametric convex hull/convex cone reference technologies based on either statistical axioms or distributional assumptions that allow for a random (estimator of the) reference technology" (p. 3).

As established by Olesen and Petersen (2016), this method uses production theory axioms such as convexity and radial modification of input and output quantities, and statistical axioms or distribution assumptions that allow efficiency to be estimated in relation to a deterministic or stochastic production possibility set. In their study, the stochastic DEA

\footnotetext{
${ }^{6}$ Greene (2008) reviews the SFA literature and demonstrates several possibilities for both the specification and estimate of the efficient frontier.
} 
confirms the complementarity of the DEA and the SFA and has bridged the gap between the interpretation of efficiency within management science and within statistics and econometrics.

There are different approaches within the stochastic DEA, as can be seen in Banker, Kotarac and Neralic (2015), which are listed without any classification proposals. In contrast, the review of the literature on stochastic DEA by Johnson (2017) provides a grouping of studies on this topic into several categories:

1. Studies considering that observations available for efficiency calculations are a random sample of production units and aim to infer the characteristics of the production technology generating these data. This group includes research by Banker (1993), which demonstrates that under certain conditions the DEA is a maximum likelihood estimator and is consistent, and the use of bootstrapping proposed by Simar and Wilson (1998) and Simar and Wilson (2000). ${ }^{7}$

2. Research based on not fulfilling the DEA inclusion assumption. ${ }^{8}$ There are two blocks within this group:

a. Research proposing solutions for imprecise data. For Hatami-Marbini, Emrouznejad and Tavana (2011) the observed input and output values in realworld problems are imprecise or vague and do not present the accuracy conventional DEA requires. This situation is resolved firstly by imprecise DEA and secondly by fuzzy DEA. Imprecise DEA was proposed by Cooper, Park and Yu (1999) and the model for imprecise data considers input amounts used and output amounts obtained as random variables with a specific density function within a range of values. According to Johnson (2017), panel data are often used in imprecise DEA, and he interprets it as a sensitivity analysis rather than as results obtained from an unknown technology and, therefore, he assigns a different purpose to other stochastic DEA models. Fuzzy DEA includes all the models that resolve the uncertainty about a certain observation belonging to the production technology by means of fuzzy methods that some authors have proposed to deal with data imprecision or ambiguity in general.

\footnotetext{
${ }^{7}$ Concern about the possibilities of inferring statistical results from the DEA has already been addressed in Simar (1996) and in Simar and Wilson (2007), and Simar (2007) proposes the use of bootstrapping for statistical inference.

${ }^{8}$ For Johnson (2017) this assumption causes the DEA results to be sensitive to outliers, to data measurement errors or specification errors in the model used.
} 
A review of the proposed methods within fuzzy DEA can be found in HatamiMarbini, Emrouznejad and Tavana (2011).

b. Studies considering the production possibility set as random and whose boundary cannot be observed. Not fulfilling the DEA's inclusion assumption in these studies allows some data to be below the isoquant's representative efficient frontier. Johnson (2017) includes two types of solutions in this group. Both have been provided by the literature but differ in the data they require and the assumptions on which they are based. The first refers to all models specifying a parameter that directly or indirectly determines how much data should lie below the frontier. The second consists of models that include random noise. The starting point in these models is estimating a regression that is as follows:

$$
y=f(x)-u+v
$$

where $\mathrm{x}$ is the vector of the random input variables, $\mathrm{y}$ is the random variable of the output quantity obtained, $\mathrm{u}$ is the non-negative random variable characterising inefficiency, and $\mathrm{v}$ is the random variable characterising random noise. Although expression (4) seems similar to the regression to be estimated in SFA, it does not represent it, because the functional form of $f(x)$ has to be specified in calculations using this tool, since it is a parametric method.

Olesen and Petersen (2016) also provide a classification of stochastic DEA studies that is almost identical to the above classification even though their starting point differs. These authors believe that DEA extensions have pursued three directions:

1. Deviations from the deterministic frontier are considered random variables.

2. Interpretation of the production possibility set is random.

3. Random noise is introduced to account for measurement errors, sample noise and specification errors in the model.

Since Olesen and Petersen (2016) explicitly state that they do not consider imprecise DEA or fuzzy DEA in stochastic DEA as both lack a statistical basis, the above classification coincides exactly with Johnson's (2017). The non-inclusion of these two approaches in stochastic DEA is also found in Wen (2015).

Two empirically applicable studies of stochastic DEA are by Sengupta (1998), who proposes a two-stage method for dealing with variations in input and output data, and by Sueyoshi 
(2000), who reformulates the stochastic DEA model to incorporate subsequent information with the aim of planning for the future rather than evaluating past performance.

\section{RESULTS}

We calculate the efficiency of Spanish football teams that have competed in the Spanish First Division between 2011 and 2016. We have chosen these seasons because our aim is to relate efficiency with sporting results and there have been three different league champions in the time horizon used in our research. Although we have considered the match as the production process to be assessed in specifying the production function, we have calculated efficiency ratios for all five of the analysed seasons and the data for every one of the input and output variables also, therefore, refer to the entire season.

The data used in our research were provided by Opta Sports. This database does not contain information on challenges, running with the ball, tackles and control. Neither does it distinguish between fouls leading to a direct free kick and an indirect free kick. This circumstance means that a shared resource appears in the representative process of possession time. Nevertheless, although this would imply a similarity with the structures described in the papers by Färe and Grosskopf (1996), Löthgren and Tambour (1999), Chen, Liang, Yang and Zhu (2006) and $\mathrm{Yu}$ and Lin (2008), the above-presented reasons for not using the network DEA are still valid. In short, the use of profiling calculates the efficiency of the subdivisions detailed in the following table:

Table 1. Processes that the production of football matches is divided into.

An apparent discrepancy is observed in the criterion of creating the subdivisions that appear in the above table and whose efficiency has been calculated. To be precise, we have separated efficiency into the conversion of fouls into shots and goals, when both outputs can also come from other resources, and the same occurs with recovered balls, which, on the one hand, appear as the result of transforming interceptions and, on the other, of throw-ins and saves. The recommendations Tofallis (1996) makes consist of valuing efficiency whereby every input is used to obtain the outputs related to it. Nevertheless, the author himself recognises that in cases in which it is certain that several inputs are substitutes to produce one or several outputs, their efficiency should be calculated jointly. He also advises against calculating the 
efficiency whereby every individual output is obtained from a combination of inputs. While it is reasonable to think that one input can be shared by several outputs, it is not true that the total quantity of every resource is consumed by only one output. In short, applying these recommendations to our work leads us to calculate the efficiency of every move; however, when more than one is used to obtain the same outputs, and only that output, we have considered substitutable resources and calculated their joint efficiency. In cases in which a move can contribute to attaining more than one output, their efficiency was calculated individually if these outputs can also stem from another type of move.

The descriptive statistic of the data used is shown in Table 2.

Table 2. Descriptive statistic.

Source: Own based on Opta Sports.

Before interpreting the efficiency ratios obtained for the football teams in the Spanish First Division, we should clarify the specification of the production function before presenting the results.

Firstly, we should question the relevance of knowing the efficiency of football teams. The general recommendation for inefficient organisations is how far they should reduce their consumption of resources if an input orientation has been considered in the calculations or the product increase they could achieve if an output orientation has been adopted. With the latter focus, the proposal to improve efficiency would translate into an improvement in sporting results. Consequently, improving the efficiency of the subdivision associated with nonpossession would increase the number of recovered balls. After recovering the ball, improving the efficiency of the possession subdivision with the aim of not losing the ball increases possession time and, consequently, the opportunity to perform typical moves during possession time for which the number of goals scored would also rise if efficiency is also increased. Similarly, an improvement in the subdivision for the goalkeeper's actions would also increase the number of prevented conceded goals. An increase in the number of scored goals and a decrease in the number of conceded goals aids match victory and, therefore, sporting success. 
Knowledge of efficiency ratios in the subdivisions for several seasons can also result in a team permanently or often appearing as efficient in some of the actions. This fact could be interpreted as an indicator of one's own particular playing style. This information can be useful for rivals since it would enable them to prepare their matches against this team by planning moves that counteract this particular style. Furthermore, if it is demonstrated that this different style of play helps improve sporting results, rivals could plan to put it in practice, which would also counteract the advantages that the first team might have been able to obtain.

Secondly, choosing the representative resources of the production function can lead to criticism because we should not only include consumed quantities in the input variables, but also some measure of their quality based on the argument that we cannot produce the same output quantity with the same provision of resources, but which have different characteristics. To justify the choice we have made in this study, we need to delve deeper into the meaning of inefficiency when, as we can learn from Farrell (1957) and Triantis (2004) and as presented in this study, only the physical quantities of consumed production resources are taken as the representative variables of inputs. In this case, efficiency differences detected between the organisations in the study sample might be due to the characteristics of these resources, for example training, skill, motivation, and so on, for human resources, and technological development for capital resources. Based on this perspective, managers of inefficient organisations know that if they want to make them efficient, they must take actions that change the attributes of their resources resulting in better use of them, in other words they can employ fewer production factors or increase their output volume with available resources. In short, the focus does not ignore the influence of these differences on the characteristics of the production resources. Instead it recognises that they are precisely the cause of differences in the efficiency of organisations.

Thirdly, since the variables taken as resources in this study are the actions performed, we must first discuss how to interpret the efficiency ratios we obtain. When a production function has been specified as used quantities of human resources and capital resources to obtain final product quantities, inefficient organisations can increase the quantity of obtained product by varying the characteristics of their production resources, how they perform the tasks they have been assigned or their internal organisation to increase the efficiency of their work. In multi-stage production processes, such as those mentioned in the network DEA literature, the recommendation that can be made to inefficient organisations is similar, but 
applicable in successive phases: they can increase efficiency in their use of their original resources to increase intermediate output quantities and, with a better provision of resources, together with better use, final product quantities would also increase. However, in our study's approach, following Schofield (1988), Carmichael and Thomas (1995) and Carmichael, Thomas and Ward (2000), it is in the first stage of sports teams' production function, in other words training sessions, in which the resources to be considered represent work and capital. Nevertheless, in the second stage - the match analysed in this paper-leveraging resources (in other words, managing to transform moves into the highest possible number of later moves) can be due to the players' skill in their own performance of the move and in preventing their rival's influence, and to the influence of their rival's game itself. The players' knowledge, expertise or skill would be the characteristics that increase efficiency in transforming moves, but they are attributes to work on and modify in the first stage. Detected inefficiencies are a consequence of the first stage and, therefore, they should be solved in that stage. In short, we can improve the efficiency of transforming moves to increase the outputs of the subdivisions into which the production function of football teams during matches has been fragmented in this study, but tasks improving players' knowledge and skill so they can perform moves better and face their rival's influence are found in the first phase.

Finally, all the above reflections only refer to using the resources. To increase product quantity, organisations also have the option of increasing their initial provision of resources. This is also the only option that has efficient DMUs. Inefficient organisations could choose between carrying out changes to be more efficient, increasing quantities of consumed resources or both. In the case studied in this research, the resources whose initial provision is increased would be moves during matches. As these are neither typical capital nor work resources that can be increased by acquisitions and hirings, respectively, the increase in the initial provision of moves (passes in possession to score a goal, running with the ball, control and dribbling in possession so as not to lose the ball, challenges, interceptions, tackles, throwins and saves in non-possession and the goalkeeper's actions) deserve further reflection. An increase in these original moves depends on the first provision of players both in number and initial characteristics (physical conditions) and the training they do to improve their knowledge and skills in performing moves, all of which must be decided, worked on, modified and organised in the first phase, which is the training phase.

In view of the above considerations, it is apparent that knowledge of the efficiency ratios of moves during matches as calculated in this study would be of additional use in helping to 
guide the decisions taken in the first stage of the production process of sporting teams. Tables 3 to 7 show the efficiency ratios obtained in every one of the seasons we analysed in our research for all the subdivisions into which the production process of the football teams during matches has been divided. The champion team for that year has been highlighted in bold in each of the tables and the other teams are shown in the position corresponding to their final classification for the season. Also highlighted are the ratios of efficient teams in the corresponding subdivision. To classify a team as efficient, besides its ratio being the same as the unit, we have checked that its slacks are zero, which ensures that the observations are actually located on the isoquant. Although Tofallis (1996 and 1997) presents forms of allocating just one efficiency ratio to DMUs for which he has calculated the profiling, and Cook, Liang and Zhu (2010) also propose possible calculations to be performed with the efficiency ratios of the production process stages when they are calculated independently, this study will deal with the ratios obtained in each of the subdivisions we have considered, since this helps teams to detect where they can better exploit their actions.

In short, the calculated efficiency ratios show how football teams have benefited from transforming moves with the role of inputs into moves taken as outputs in each of the subdivisions into which a match has been fragmented. These ratios have been calculated on an output orientation to discover the increase in the number of moves that each team could have achieved based on input actions actually performed. With these considerations, and from the standpoint of using resources, teams should be efficient in non-possession tasks to gain the ball as often as possible from interceptions, throw-ins and saves. Nevertheless, ball possession is not a team's main aim during a match. Instead, once they have the ball they should try to score a goal. To do that they must attempt not to lose the ball and link the necessary moves to score a goal. Consequently, again from an efficiency standpoint, the recommendation is for the number of completed moves to be as high as possible. Lastly, since the victorious team in a match is the one that has scored the most goals, the goalkeeper's actions aimed at preventing his opponent's goals can also be considered a subdivision of the production process during a match and, therefore, subject to the assessment of their efficiency, in other words obtaining maximum amounts.

Table 3. Efficiency results for the 2011/2012 season

Table 4.- Efficiency results for the 2012/2013 season 
Table 5.- Efficiency results for the 2013/2014 season

Table 6.- Efficiency results for the 2014/2015 season

Table 7.- Efficiency results for the 2015/2016 season

In line with our approach to the production function of football teams in our research, no team has proved to be efficient in all the subdivisions considered in this paper and the efficiency ratios equal to the unit of the subdivisions considered are distributed among different teams, which can be indicative of various game styles. The results obtained from calculating efficiency in the sample that has been used as an example in this study demonstrate, firstly, that efficiency ratios with values equal to the unit are concentrated in teams in the top positions in the classification table. This indicates that teams demonstrating sporting success during their matches are best at transforming their moves into the type of moves for which they were designed. Although this falls outside the scope of this study, an analysis should be conducted of whether the number of initial moves is also more in these teams. If this was the case, their sporting success would be due to both good use of the moves and number of them with which they can begin the series of actions considered in this research; otherwise, we could say that efficiency in using their resources is a determining factor in their success.

Continuing with the analysis of the efficiency of the teams in the top positions in the table, they are efficient in more than one subdivision and even in several in possession and nonpossession tasks. Furthermore, a different style of play was detected between Real Madrid, Barcelona and Atlético de Madrid, which were champions in some of the seasons analysed in this research. While Real Madrid is essentially efficient in the subdivisions of ball possession, Atlético de Madrid is efficient in the subdivisions of non-possession; only in the last analysed season did Atlético de Madrid show efficiency in converting shots and penalties into goals. Real Madrid showed efficiency in the two parts that non-possession has been subdivided into. Nevertheless, we also observed that Barcelona is efficient in converting shots and penalties into goals in all the analysed seasons, in other words this team could increase the number of goals it scores by improving its use of previous moves leading to shots, since this team is highly efficient in conversion and goal penalties.

In conclusion, teams can show more efficiency in ball possession or in non-possession (this will depend on training sessions, the players' characteristics and the coach's decisions and 
approaches), but in the Spanish First Division at least it has not been proved that one contributes more than the other to sporting success. Efficiency in the subdivision referring to the goalkeeper's actions would appear in the Spanish case not to contribute to sporting success because efficient teams in that subdivision are usually in the second half of the table, with the exception of Barcelona in the 2012-2013 season (which it won) and Barcelona and Madrid in the 2015-2016 season.

Teams demonstrating ratios equal to one, but which do not occupy the top positions in the table, are only efficient in one subdivision, except for Zaragoza in the 2012-2013 season and Elche and Getafe in the 2014-2015 season.

Concerning teams for whom we can deduce a particular style of play from the results, the case of Granada is worth mentioning since it has been efficient in transforming assists and corners into shots in all the seasons since 2012. Similarly, Valencia proved efficient in transforming the goalkeeper's actions into saves and saved penalties from 2013 to 2016. Given that this ratio equal to the unit appears more tan once, we could consider that these two teams have a particular style of play that could be analysed by their rivals to counteract these two teams' good use of moves in the above-mentioned subdivisions.

Another result worth highlighting is the high efficiency values achieved by all the analysed teams throughout the time horizon of this research in transforming interception into clearances and recovered balls. Given that this was a general observation, it could be considered characteristic of the Spanish First Division League Championship.

Finally, Racing de Santander in the 2011-2012 season and Zaragoza in 2012-2013 are the teams classified in last place and they demonstrate ratios equal to one in some of the subdivisions we studied. The former team shows a high efficiency in non-possession, so we could say that they appropriately use moves that lead to ball recovery; however, in possession subdivisions, their exploitation of moves is low so they score fewer goals than the number they could have obtained from an efficiency standpoint. Zaragoza efficiently transforms the goalkeeper's actions so they prevent their rivals from scoring goals; however, given that their efficiency ratios in ball possession are so low, they do not score all the goals that could have resulted from their moves, which could be the reason for their failure as they did not manage to score enough goals to beat those scored against them in the matches they played throughout the competition. 
The football match production process addressed in this study does not correspond to a typical production process in which the factor quantities acquired (material resources purchased or workers hired) are transformed into physical products by a mechanical process. In the case of football matches, the equivalent to the production process is labour-intensive, and this makes it difficult to standardise the activity, which is the basis for putting into practice the numerical results obtained from the original DEA. If the number of any move the team performs deviates slightly from the specified value to be efficient, this does not have a huge impact on the game, but the mathematical accuracy of the solution of the linear programming problem, which is the DEA, would qualify that team as inefficient. The above could be interpreted as an example of the volatility of resources and products, which, according to Wen (2015), occurs in many situations and would justify the use of stochastic DEA models addressing data variation, since an exact measurement of inputs and outputs is required for the DEA to be a suitable tool for measuring efficiency since DEA results are sensitive to the data used. A stochastic DEA method that Banker, Kotarac and Neralic (2015) and Olesen and Petersen (2016) propose when panel data are available and possible measurement errors have to be addressed (as in the case in this paper) is presented in Ruggiero (2004). This author states that for every DMU, the difference between the actual value of its efficiency ratio and the value resulting from DEA calculations may be due to measurement errors in this DMU's input and output data and to the shift these measurement errors cause at the estimated efficient frontier compared with the actual frontier. According to Ruggiero (2004), the availability of panel data for calculating the efficiency of a sample of DMUs solves the stochastic frontier problems detected in Ondrich and Ruggiero (2001). In fact, the distinction between inefficiency and measurement errors, which is the crucial advantage that the approach based on statistics and econometrics gives to the SFA, is favoured by the additional information provided by time series to identify efficiency and it also avoids the a priori assumption of statistical distributions for efficiency and error. As a method for calculating efficiency, this author proposes applying the DEA to average input and output values over the years considered in the data panel to average out the two types of errors that may occur. Since the advantages of using this method to calculate efficiency are its simplicity, ease of interpreting the results and its usefulness in verifying the robustness of the original DEA version, it was deemed appropriate for this study, in which a management science approach was adopted to measure and analyse efficiency. 
The championship rules of the Spanish First Division League relegate the three worst classified teams at the end of the season to the Second Division and add the three best classified teams from the category immediately below. Therefore, in the sample under study, the teams participating in the championship were not the same throughout the analysed years. There are two solutions for moving from the data panel with the initial information to the average input and output values proposed by Ruggiero (2004): only considering the teams that remained in the First Division League throughout all the seasons between 2011 and 2016, or considering all of them and calculating the average moves each made during the years in which they participated in this championship throughout this study's time horizon. The second alternative was chosen to have more degrees of freedom in applying the DEA.

Table 8 shows the results of the efficiency calculation following the proposal made by Ruggiero (2004) to address the abovementioned imprecision in the data. Since these results stem from information over several seasons, the teams appear in alphabetical order and their position in that table does not relate to their sporting results.

Table 8. Efficiency results applying the proposal made by Ruggiero (2004).

Throughout the seasons analysed in this research, the Spanish First Division League champions were Atlético de Madrid, Barcelona and Real Madrid. Table 8 shows that, besides Valladolid, these three teams demonstrate an efficient use of their moves in more than one subdivision. Furthermore, Real Madrid is efficient in all ball possession subdivisions and Barcelona and Atlético de Madrid are efficient in the two subdivisions into which nonpossession is divided, thus corroborating that sporting success is possible by being efficient in both possession and non-possession moves. This result was also arrived at by calculating the efficiency of the sample of football teams in this study with the original DEA.

It is also evident from the results in table 8 that efficient teams in actions performed by the goalkeeper have not achieved remarkable sporting success in the seasons between 2011 and 2016 (the highest position achieved by Valencia was third place in the 2011/2012 season and Racing Santander, Sporting de Gijón and Valladolid did not remain in the First Division throughout all the years studied). The season-by-season DEA calculations have also shown the absence of a link between efficiency in the goalkeeper's moves and sporting successes. Similarly, the results obtained with the original DEA and the stochastic DEA coincide for the 
high efficiency shown by all the teams analysed in the subdivision that converts interceptions into clearances and recovered balls.

Teams demonstrating efficiency in some ball possession or non-possession subdivisions are Eibar (conversion of throw-ins and saves into recovered balls), Mallorca (conversion of interception into clearances and recovered balls) and Osasuna (conversion of shots and penalties received into goals). Valladolid is efficient in the goalkeeper's actions and in converting dribbles into passes, assists and shots. The particular cases of Valencia, Granada, Racing de Santander and Zaragoza detected in the original DEA are not observed in the results obtained with the stochastic DEA.

\section{CONCLUSIONS}

Since professional football teams form a sector that is not subject to the laws of the perfect competition model, the organisations in it might not be efficient and calculating their efficiency is, therefore, relevant. Our study is based on the specification of the production function of football teams taking the production process as a starting point. We have aimed to open the 'black box' of this process in this specification and, based on the technical relationships between moves and then non-substitutability to obtain a goal, we have considered eight subdivisions.

The calculations show teams in which subdivisions in the production process (in this case a football match) players can improve their use of moves to transform them into the next actions with the ultimate aim of scoring a goal, recovering the ball or preventing the opposing team from scoring. Improving efficiency in transforming moves requires work in the production process stage comprising training sessions. The results we have obtained show that some teams are more efficient in moves during possession time and others are more efficient during non-possession. However, neither of these two alternatives has proved to be better from the viewpoint of sporting results since examples of both have been found in the league champions studied in this research. This result can be considered robust since it is also arose from applying the stochastic DEA.

From an academic point of view, this research contributes to the study of the efficiency of football teams: it approaches the series of moves as Blass (1992), Carmichael, Thomas and Ward (2001) and Deli (2012) do, as a means of opening the 'black box', in other words, the manner in which matches had previously been addressed as the representation of teams' 
production function (all the actions served to obtain the sporting results). Thanks to the use of profiling, this series has been analysed exclusively considering technical issues without the need to modify or adapt it to any of the production structures outlined in the literature on the network DEA.

This study is based on the DEA as the efficiency calculation tool. This well-established and often-used tool in the academic world adopts a management science approach and may be of use to the managers, coaches and analysts of football teams and, in general, of team-sport competitions because it demonstrates a means of discovering how to best exploit resources (own moves) to devise their game plan.

The results we have presented are not limited to highlighting the numerical values we have obtained, since we first provided a general discussion on all the situations that could arise, the reasons for them and how they are used. It is true that one limitation of our proposal is the difficulty in distinguishing whether low exploitation of the moves of inefficient teams is due to failures attributable to the team (such as lack of skills or preparation, which, strictly speaking, would be inefficiency) or the actions of rivals that have prevented moves from ending in the intended action. In this study, taking the data for the entire season as a reference for the analysis has solved this problem since all the teams have played the others and all have experienced the same pressure from their rivals. If the method proposed in our research was applied to a competition in which not all the participants were homogenous, this could be solved by taking the match as a unit of analysis, for example, and forming the sample with the data of all the teams that have played the same rival. Similarly, if a team changes strategy in every match depending on who their rival is, conducting the analysis proposed in this paper per match would also be advisable. In any case, the use of the stochastic DEA also helps to solve these problems.

In the case studied in this paper, and given the subdivision structure considered representative of the activity performed during a match, knowledge of which subdivisions a team is inefficient in highlights which actions are consuming excessive resources in the form of moves that could be transformed into a higher output, in other words, other moves. This increase in moves obtained in the subdivisions detected as inefficient passes through the first stage of the production function of football teams outlined in the research by Schofield (1988), Carmichael and Thomas (1995) and Carmichael, Thomas and Ward (2000), in other words, all the activity prior to the match. Therefore, the results in this paper could guide the 
physical preparation tasks of players during training sessions, tactical and strategic plans for matches and even the physical characteristics of the players that are eventually hired.

The calculation method and analysis of the efficiency of football teams presented in this paper provide trainers, managers, advisers and specialists with information on which subdivisions of match activity could better use the moves made. The results can also tell teams where their rivals are exploiting moves well so that the former can either imitate the latter, adapt to the situation and counteract it or differentiate themselves from their opponents. Planning a new or more common style of play is a matter that the team's coach needs to determine.

\section{REFERENCES}

Andersen, P., \& Petersen, N. C. (1993). A Procedure for Ranking Efficient Units in Data Envelopment Analysis. Management Science, 39(10), 1261-1264.

Banker, R. (1993). Maximum Likelihood, Consistency and Data Envelopment Analysis: A Statistical Foundation. Management Science, 39(10), 1265-1273.

Banker, R., Kotarac, K., \& Neralic, L. (2015). Sensitivity and stability in stochastic data envelopment analysis. Journal of the Operational Research Society, 66(1), 134-147.

Blass, A. (1992). Does the baseball labor market contradict the Human Capital Model of investment? The review of Economics and Statistics, 74(2), 261-268.

Cantarero, C. (1995). Escuela de Fútbol. Del aprendizaje a la alta competición. Editorial Tutor.

Carmichael, F., \& Thomas, D. (1995). Production and efficiency in team sports: an investigation of rugby league football. Applied Economics, 27(9), 859-869.

Carmichael, F., Thomas, D., \& Ward, R. (2000). Team Performance: The Case of English Premiership Football. Managerial and Decision Economics, 21(1), 31-45.

Carmichael, F., Thomas, D., \& Ward, R. (2001). Production and Efficiency in Association Football. Journal of Sports Economics, 2(3), 228-243.

Castelli, L., Pesenti, R., \& Ukovich, W. (2010). A classification of DEA models when the internal structure of the Decision Making Units is considered. Annals of Operations Research, 173(1), 207-235.

Chen, Y., \& Zhu, J. (2004). Measuring Information Technology's Indirect Impact on Firm Performance. Information Technology and Management, 5(1-2), 9-22. 
Chen, Y., Liang, L., Yang, F., \& Zhu, J. (2006). Evalutation of information technology investment: a data envelopment analysis approach. Computers and operations research, 33(5), 1368-1379.

Chilingerian, J. A., \& Sherman, H. (2004). Health Care Applications. En W. Cooper, L. Seiford, \& J. Zhu, Handbook on Data Envelopment Analysis (págs. 481-537). Boston, Dordrecht, London: Kluwer Academic Publishers.

Cook, W. D., Liang, L., \& Zhu, J. (2010). Measuring performance of two-stage network structures by DEA: A review and future perspective. Omega, 38(6), 423-430.

Cook, W. D., Tone, K., \& Zhu, J. (2014). Data envelopment analysis: Prior to choosing a model. Omega, 44, 1-4.

Cooper, W., Park, K., \& Yu, G. (1999). IDEA and AR-IDEA: Models for Dealing wiht Imprecise Data in DEA. Management Science, 45(4), 597-607.

Deli, D. (2012). Assessing the Relative Importance of Inputs to a Production Funcion: Getting on Base Versus Hitting for Power. Journal of Sports Economics, 14(2), 203217.

Despotis, D. K., Sotiros, D., \& Koronakos, G. (2016). A network DEA approach for series multi-stage processes. Omega, 61, 35-48.

Dobson, S., \& Goddard, J. (2010). Optimizing strategic behaviour in a dynamic setting in professional team sports. European Journal of Operational Research, 205(3), 661669.

Doyle, J., \& Green, R. (1994). Efficiency and Cross-efficiency in DEA: Derivations. Meanings and Uses. Journal of the Operational Research Society, 45(5), 567-578.

Espitia-Escuer, M., \& García-Cebrián, L. (2004). Measuring the Efficiency of Spanish FirstDivision Soccer Teams. Journal of Sports Economics, 5(4), 329-346.

Färe, R., \& Grosskopf, S. (1996). Productivity and intermediate products: A frontier approach. Economics Letters, 50, 65-70.

Färe, R., \& Lovell, C. (1978). Measuring the Technical Efficiency of Production. Journal of Economic Theory, 19(1), 150-162.

Farrell, M. (1957). The Measurement of Productive Efficiency. Journal of the Royal Statistical Society. Series A (General) , 120(3), 253-290 .

García-Sánchez, I. M. (2007). Efficiency and effectiveness of Spanish football temas: A three-stage-DEA approach. Central European Journal of Operations Research, 15(1), $21-45$.

Golany, B., \& Roll, Y. (1989). An Application Procedure for DEA. Omega, 17(3), 237-250. 
Gómez-López, M., \& Álvaro-Alcalde, J. (2002). El tiempo de posesión como variable no determinante del resultado en los partido de fútbol. El entrenador español, 97, 39-47.

Greene, W. (2008). The Econometric Approah to Efficiency Analysis. En H. Fried, C. Lovell, \& S. Schmidt, The Measurement of Productive Efficiency and Productivity Growth (págs. 92-250). New York: Oxford University Press.

Guzmán, I. (2006). Measuring Efficiency and Sustainable Growth in Spanish Football Teams. European Sport Management Quarterly, 6(3), 267-287.

Haas, D. J. (2003 a). Productive Efficiency of English Football Teams. A Data Envelopment Analysis Approach. Managerial and Decision Economics, 24(5), 403-410.

Haas, D. J. (2003 b). Technical Efficiency in the Major League Soccer. Journal of Sports Economics, 4(3), 203-2015.

Haas, D., Kocher, M. G., \& Sutter, M. (2004). Measuring Efficiency of German Football Teams by Data Envelopment Analysis. Central European Journal of Operations Research, 12(3), 251-268.

Hatami-Marbini, A., Emrouznejad, A., \& Tavana, M. (2011). A taxonomy and review of the fuzzy data envelopment analysis literature: Two decades in the making. European Journal of Operational Research, 214(3), 457-472.

Hughes, M. D., \& Bartlett, R. M. (2002). The use of performance indicators in performance analysis. Journal of Sports Sciences, 20(10), 739-754.

Johnson, A. (2017). Stochastic DEA: The regression-based approach. En K. Tone, Advances in DEA Theory and Applications. With Extensions to forecasting models (págs. 8599). John Wiley \& Sons Ltd.

Jones, P. D., James, N., \& Mellalieu, S. D. (2004). Possession as a performance indicator in soccer. International Journal of Performance Analysis in Sport, 4(1), 98-102.

Kao, C. (2012). Efficiency decomposition for parallel production systems. Journal of the Operational Research Society, 63(1), 64-71.

Kao, C. (2014). Network data envelopment analysis: A review. European Journal of Operational Research, 239(1), 1-16.

Kao, C., \& Hwang, S.-N. (2008). Efficiency decomposition in two-stage data envelopment analysis: An application to non-life insurance companies in Taiwan. European Journal of Operational Research, 185(1), 418-429.

Kern, A., Schwarzmann, M., \& Wiedenegger, A. (2012). Measuring the efficiency of English Premier League football. Sport, Business and Management: An International Journal, 2(3), 177-195. 
Lago, C., \& Martín, R. (2007). Determinants of possession of the ball in soccer. Journal of Sports Sciences, 25(9), 969-974.

Lei, X., Li, Y., Xie, Q., \& Liang, L. (2015). Measuring Olympics achievements based on a parallel DEA approach. Annals of Operations Research, 226(1), 379-396.

Lewis, H. F., Lock, K. A., \& Sexton, T. R. (2009). Organizationl capability, efficiency, and effectiveness in Major League Baseball: 1901-2002. European Journal of Operational Research, 197(2), 731-740.

Li, Y., Lei, X., Dai, Q., \& Liang, L. (2015). Performance evaluation of participating nations at hte 2012 London Summer Olympics by a two-stage data envelopment analysis. European Journal of Operational Research, 243(3), 964-973.

Liu, J. S., Lu, L. Y., \& Lu, W.-M. (2016). Research fornts in data envelopment analysis. Omega, 58, 33-45.

Liu, J. S., Lu, L. Y., Lu, W.-M., \& Lin, B. J. (2013). Data envelopment analysis 1978-2010: A citation-based literature survey. Omega, 41(1), 3-15.

Löthgren, M., \& Tambour, M. (1999). Productivity and customer satisfaction in Swedish pharmacies: A DEA network model. 115, 449-458.

Lovell, C., Walters, L., \& Wood, L. (1994). Stratified models of education production using modified DEA and regression analysis. En A. Charnes, W. Cooper, A. Lewin, \& L. Seiford , Data Envelopment Analysis: Theory, Methodology, and Application (págs. 329-351). Boston, Dordrecht, London: Kluwer Academic Publishers.

Menéndez, H., Bello-Orgaz, G., \& Camacho, D. (2013). Extracting behavioural models form 2010 FIFA World Cup. Journal of Systems Science and Complexity, 26(1), 43-61.

Moreno, P., \& Lozano, S. (2014). A network DEA assessment of team efficiency in the NBA. Annals of Operations Research, 214(1), 99-124.

Moreno, P., \& Lozano, S. (2015). Estimation of Productivity Change of NBA Teams from 2006-07 to 2012-2013 Seasons. International Journal of Sport Finance, 10(3), 217241.

Olesen, O., \& Petersen, N. C. (2016). Stochastic Data Envelopment Analysis-A review. European Journal of Operational Research, 251(1), 2-21.

Ondrich, J., \& Ruggiero, J. (2001). Efficiency measurement in the stochastic frontier model. European Journal of Operational Research, 129(2), 434-442.

Pollard, R., \& Reep, C. (1997). Measuring the effectiveness of playing strategies at soccer. The Statistician, 46(4), 541-550.

Ruggiero, J. (2004). Data envelopment analysis with stochastic data. Journal of the Operational Research Society, 55(9), 1008-1012. 
Schofield, J. (1988). Production functions in the sports industry: an empirical analysis of professional cricket. Applied Economics, 20(2), 177-193.

Sengupta, J. (1998). Stochastic data envelopment analysis: a new approach. Applied Economics Letters, 5(5), 287-290.

Sexton, T. R., \& Lewis, H. F. (2003). Two-Stage DEA: An Application to Mahor League Baseball. Journal of Productivity Analysis, 19(2-3), 227-249.

Simar , L. (1996). Aspects of statistical analysis in DEA-type frontier models. Journal of Productivity Analysis, 7(2-3), 177-185.

Simar, L. (2007). How to improve the performances of DEA/FDH estimators in the presence of noise? Journal of Productivity Analysis, 28(3), 183-201.

Simar, L., \& Wilson, P. (1998). Sensitivity Analysis of Efficiency Scores: How to Bootstrap in Nonparametric Frontier Models. Management Science, 44(1), 49-61.

Simar, L., \& Wilson, P. (2000). A general methodology for bootstrapping in non-parametric frontier models. Journal of Applied Statistics, 27(6), 779-802.

Simar, L., \& Wilson, P. (2007). Estimation and inference in two-stage, semi-parametric models of production processes. Journal of Econometrics, 136(1), 31-64.

Sueyoshi, T. (2000). Stochastic DEA for restructure strategy: an application to a Japanese petroleum company. Omega, 28(4), 385-398.

Tenga, A., Holme, I., Ronglan, L. T., \& Bahr, R. (2010 a). Effect of playing tactics on achieving score-box possessions in a random series of team possessions from Norwegian professional soccer matches. Journal of Sports Sciences, 28(3), 245-255.

Tenga, A., Holme, I., Ronglan, L. T., \& Bahr, R. (2010 b). Effect of playing tactics on goal socring in Norwegian professional soccer. Journal of Sports Sciences, 28(3), 237-244.

Tofallis, C. (1996). Improving Discernment in DEA Using Profiling. Omega, 24(3), 361-364.

Tofallis, C. (1997). Input Efficiency Profiling: An Application to Airlines. Computers \& Operations Research, 24(3), 253-258.

Tone, K. (2001). A slacks-based measure of efficiency in data envelopment analysis. European Journal of Operational Research, 130(3), 498-509.

Triantis, K. P. (2004). Engineering applications of Data Envelopment Analysis. In W. W. Cooper, L. M. Seiford, \& J. Zhu (Eds.), Handbook on Data Envelopment Analysis (pp. 401-441). Boston/Dordrecht/London: Kluwer Academic Publishers.

Villa, G., \& Lozano, S. (2016). Assessing the scoring efficiency of a football match. European Journal of Operational Research, 255(2), 559-569.

Wen, M. (2015). Uncertain Data Envelopment Analysis. Berlin: Springer-Verlag. 
Yang, C.-H., Lin, H.-Y., \& Chen, C.-P. (2014). Measuring the efficiency of NBA teams: additive efficiency decomposition in two-stage DEA. Annals of Operations Research, 217(1), 565-589.

Yu, M.-M., \& Lin, E. T. (2008). Efficiency and effectiveness in railway performance using a multi-activity network DEA model. Omega, 36, 1005-1017. 


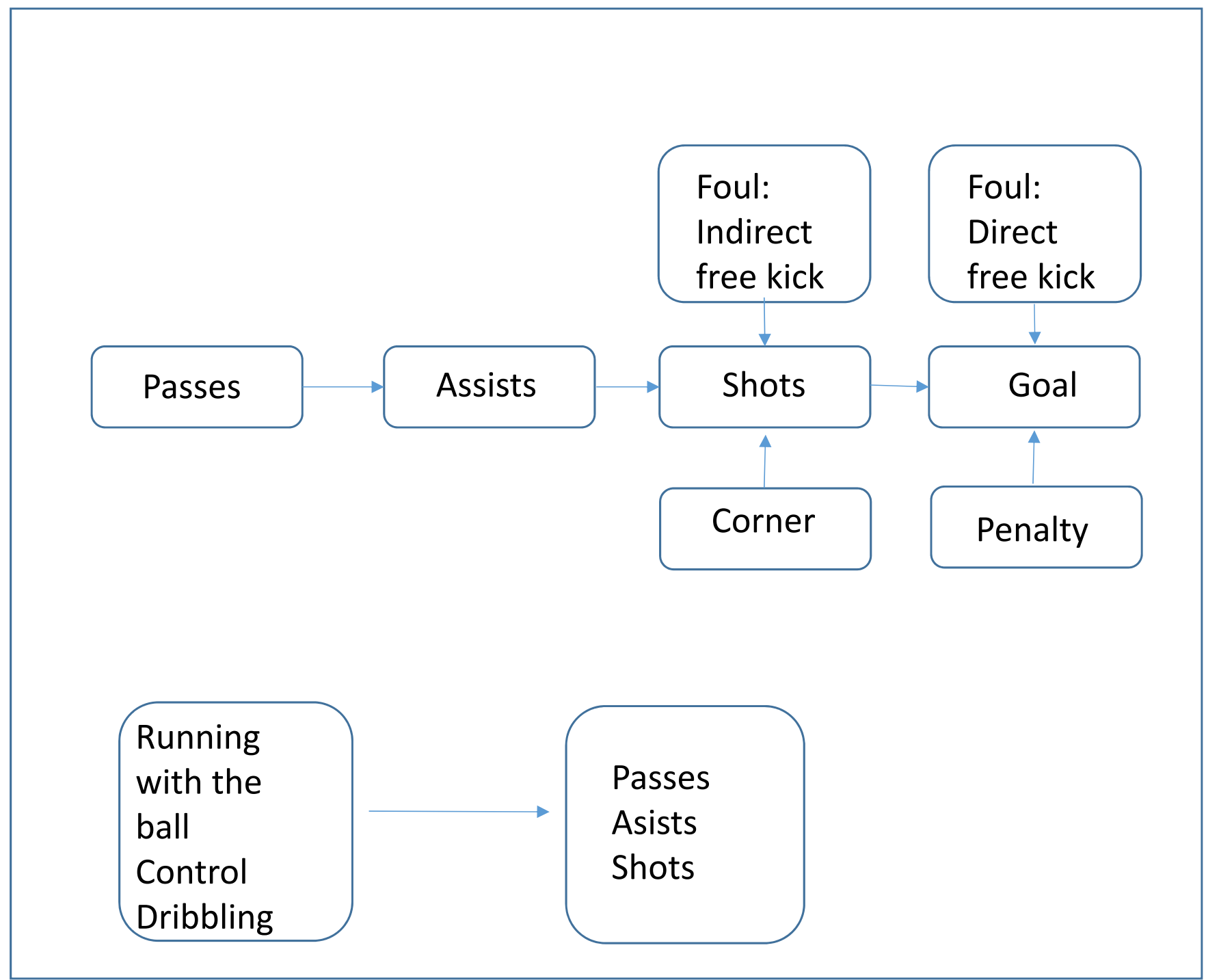

Graph 1. Sequence of moves during ball possession. 


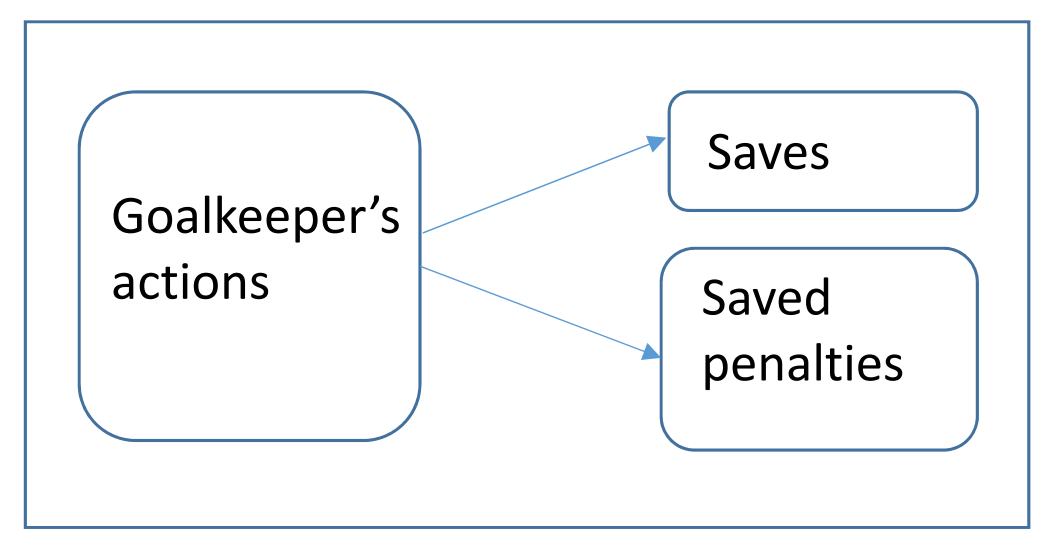

Graph 2. Sequence of goalkeeper's moves 


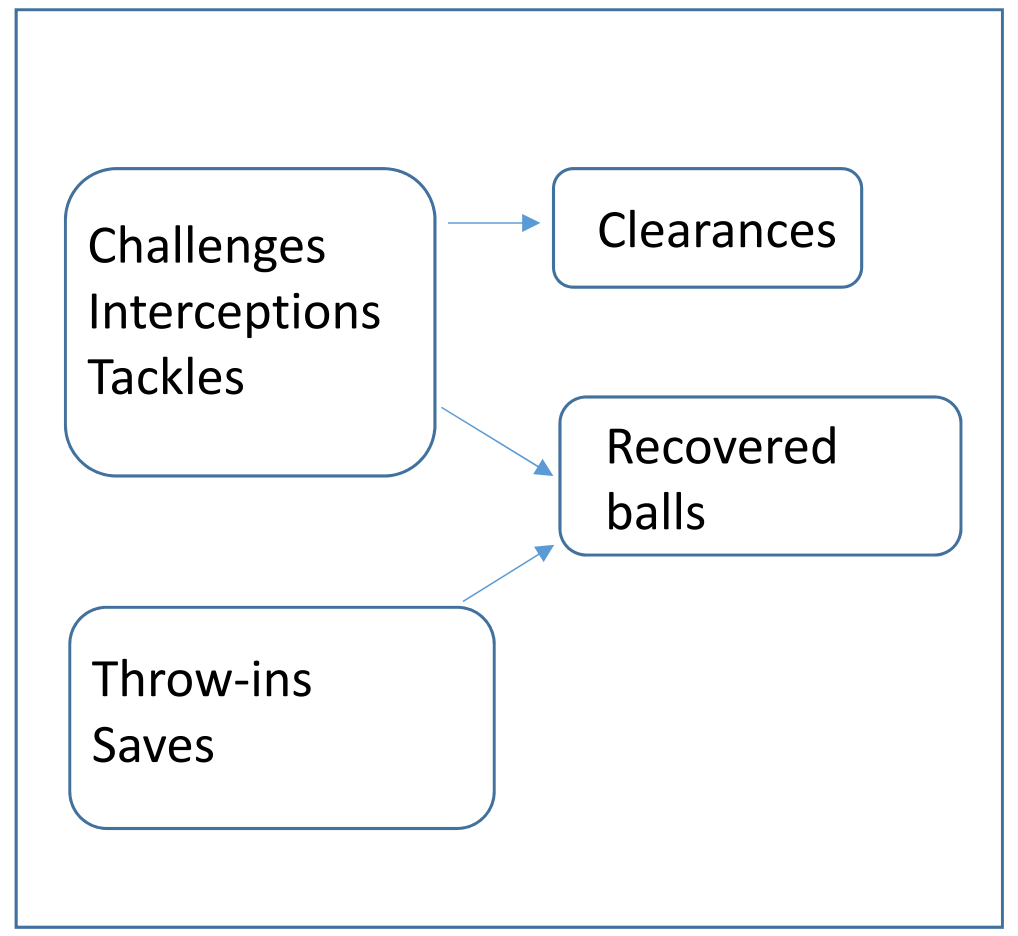

Graph 3. Sequence of moves during non possession of the ball 
Table 1. Processes that the production of football matches is divided into.

\begin{tabular}{|c|c|c|c|}
\hline \multicolumn{2}{|l|}{ SUBDIVISION } & INPUTS & OUPUTS \\
\hline \multirow{4}{*}{$\begin{array}{l}\text { Possession time } \\
\text { (actions aimed to } \\
\text { score a goal) }\end{array}$} & 1 & Passes & Assists \\
\hline & 2 & Assists, Corners & Goal shots \\
\hline & 3 & Fouls & Goal shots, Goal \\
\hline & 4 & Goal shots, penalties & Goal \\
\hline $\begin{array}{c}\text { Possession time } \\
\text { (actions aimed not } \\
\text { to lose ball) }\end{array}$ & 5 & Dribbling & Passes, Assists, Goal shots \\
\hline \multirow{2}{*}{ Non-possession time } & 6 & Interceptions & Clearances, Recovered balls \\
\hline & 7 & Throw-ins, Saves & Recovered balls \\
\hline $\begin{array}{c}\text { Goalkeeper's } \\
\text { actions }\end{array}$ & 8 & Goalkeeper's actions & Saves, Saved penalties \\
\hline
\end{tabular}


Table 2. Descriptive statistic.

\begin{tabular}{|c|c|c|c|c|c|c|c|c|c|c|c|c|c|c|c|c|}
\hline Season & & Passes & Assists & Corners & Shots & Fouls & Penalties & Goals & Dribbling & \begin{tabular}{|} 
Intercepti \\
on
\end{tabular} & $\begin{array}{c}\text { Throw- } \\
\text { ins }\end{array}$ & $\begin{array}{c}\text { Clearan } \\
\text { ces }\end{array}$ & $\begin{array}{c}\text { Recovered } \\
\text { balls }\end{array}$ & $\begin{array}{l}\text { Goalkeepe } \\
\text { r's actions }\end{array}$ & Saves & $\begin{array}{c}\text { Saved } \\
\text { penalties }\end{array}$ \\
\hline \multirow{4}{*}{ 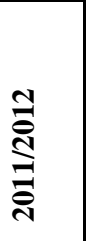 } & Maximum & 28126 & 497 & 263 & 711 & 642 & 12 & 121 & 1300 & 3911 & 1107 & 4897 & 2919 & 278 & 153 & 3 \\
\hline & Minimum & 13861 & 241 & 149 & 344 & 421 & 1 & 28 & 828 & 2956 & 795 & 3494 & 2568 & 131 & 71 & 0 \\
\hline & Average & 17699.20 & 327.20 & 200.95 & 477.50 & 539.10 & 4.80 & 52.50 & 1019.20 & 3429.80 & 950.90 & 4230.15 & 2719.80 & 226.90 & 123.05 & 0.80 \\
\hline & S. Deviation & 3216.209 & 62.673 & 34.406 & 85.710 & 45.396 & 2.857 & 22.890 & 121.184 & 193.358 & 73.206 & 288.953 & 89.095 & 38.342 & 21.892 & 0.812 \\
\hline \multirow{4}{*}{ 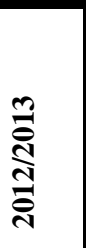 } & Maximum & 30277 & 497 & 256 & 698 & 619 & 9 & 115 & 1315 & 3882 & 1168 & 4823 & 2991 & 278 & 171 & 2 \\
\hline & Minimum & 13100 & 262 & 165 & 384 & 414 & 1 & 33 & 769 & 2926 & 842 & 3480 & 2510 & 127 & 77 & 0 \\
\hline & Average & 17900.20 & 338.65 & 213.95 & 491.65 & 534.95 & 5.45 & 54.55 & 1010.25 & 3334.50 & 982.75 & 4127.55 & 2651.35 & 226.20 & 124.45 & 0.50 \\
\hline & S. Deviation & 3425.278 & 55.066 & 27.994 & 70.601 & 46.976 & 2.156 & 20.910 & 124.155 & 179.608 & 79.790 & 254.603 & 110.579 & 35.267 & 20.910 & 0.671 \\
\hline \multirow{4}{*}{ 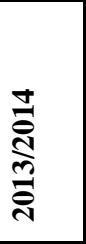 } & Maximum & 26955 & 541 & 269 & 732 & 583 & 12 & 104 & 1376 & 3461 & 1074 & 4218 & 2932 & 274 & 165 & 4 \\
\hline & Minimum & 12679 & 228 & 142 & 360 & 460 & 0 & 30 & 726 & 2953 & 804 & 3481 & 2358 & 169 & 74 & 0 \\
\hline & Average & 17696.30 & 324.35 & 211.70 & 477.45 & 524.05 & 5.75 & 52.25 & 1024.65 & 3217.05 & 934.60 & 3888.70 & 2605.30 & 221.10 & 118.60 & 1.10 \\
\hline & S. Deviation & 3020.228 & 72.396 & 27.190 & 85.957 & 37.748 & 3.144 & 21.227 & 162.389 & 130.587 & 71.796 & 181.636 & 134.697 & 28.089 & 23.701 & 0.889 \\
\hline \multirow{4}{*}{ 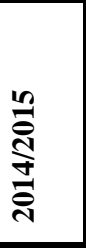 } & Maximum & 27586 & 496 & 239 & 681 & 628 & 13 & 118 & 1268 & 3543 & 1045 & 4323 & 2835 & 300 & 157 & 4 \\
\hline & Minimum & 13854 & 229 & 155 & 352 & 443 & 2 & 22 & 811 & 2869 & 723 & 3397 & 2329 & 131 & 66 & 0 \\
\hline & Average & 17460.90 & 297.40 & 193.90 & 447.40 & 532.85 & 5.45 & 50.45 & 988.60 & 3206.60 & 904.60 & 3916.40 & 2556.15 & 213.95 & 109.90 & 0.90 \\
\hline & S. Deviation & 3054.155 & 65.289 & 25.223 & 78.122 & 41.237 & 2.711 & 24.752 & 111.414 & 151.135 & 81.901 & 216.351 & 128.183 & 40.783 & 20.499 & 0.943 \\
\hline \multirow{4}{*}{ 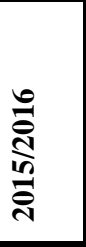 } & Maximum & 25506 & 515 & 257 & 696 & 623 & 19 & 112 & 1176 & 3398 & 1061 & 4206 & 2764 & 250 & 148 & 3 \\
\hline & Minimum & 14707 & 239 & 145 & 345 & 423 & 1 & 34 & 755 & 2868 & 708 & 3451 & 2364 & 155 & 85 & 0 \\
\hline & Average & 17851.80 & 304.25 & 192.60 & 444.90 & 506.55 & 4.85 & 52.20 & 955.50 & 3205.25 & 880.95 & 3950.95 & 2567.20 & 205.20 & 114.20 & 0.95 \\
\hline & S. Deviation & 2679.505 & 62.619 & 28.002 & 77.136 & 53.277 & 3.940 & 20.810 & 102.789 & 151.827 & 81.973 & 216.579 & 116.475 & 31.800 & 17.215 & 0.973 \\
\hline
\end{tabular}

Source: Own based on Opta Sports. 
Table 3. Efficiency results for the 2011-2012 season

\begin{tabular}{|c|c|c|c|c|c|c|c|c|}
\hline \multirow{2}{*}{ Teams } & \multicolumn{4}{|c|}{ Possession (to score a goal) } & \multirow{2}{*}{ 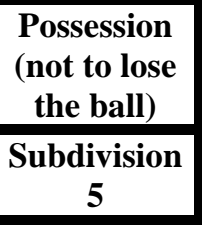 } & \multicolumn{2}{|c|}{ Non possession } & \multirow{2}{*}{$\begin{array}{c}\text { Goalkeeper's } \\
\text { actions } \\
\text { Subdivision } \\
8 \\
\end{array}$} \\
\hline & $\begin{array}{c}\text { Subdivision } \\
1\end{array}$ & $\begin{array}{c}\text { Subdivision } \\
2\end{array}$ & $\begin{array}{c}\text { Subdivision } \\
3\end{array}$ & $\begin{array}{c}\text { Subdivision } \\
4\end{array}$ & & $\begin{array}{c}\text { Subdivision } \\
6\end{array}$ & $\begin{array}{c}\text { Subdivision } \\
7\end{array}$ & \\
\hline Real Madrid & 1.004 & 1.000 & 1.000 & 1.098 & 1.000 & 1.012 & 1.045 & 1.292 \\
\hline Barcelona & 1.561 & 1.056 & 1.185 & 1.000 & 1.001 & 1.000 & 1.000 & 1.115 \\
\hline Valencia & 1.277 & 1.110 & 1.335 & 1.142 & 1.000 & 1.013 & 1.197 & 1.352 \\
\hline Málaga & 1.220 & 1.092 & 1.627 & 1.025 & 1.258 & 1.000 & 1.130 & 1.179 \\
\hline At. Madrid & 1.005 & 1.128 & 1.208 & 1.669 & 1.212 & 1.009 & 1.173 & 1.287 \\
\hline Levante & 1.310 & 1.028 & 1.666 & 1.305 & 1.439 & 1.009 & 1.113 & 1.003 \\
\hline Osasuna & 1.240 & 1.006 & 1.436 & 1.142 & 1.081 & 1.005 & 1.209 & 1.330 \\
\hline Mallorca & 1.179 & 1.115 & 1.319 & 1.650 & 1.153 & 1.001 & 1.160 & 1.129 \\
\hline Sevilla & 1.000 & 1.098 & 1.253 & 1.568 & 1.006 & 1.032 & 1.039 & 1.120 \\
\hline Athletic Club & 1.507 & 1.077 & 1.687 & 1.170 & 1.127 & 1.012 & 1.160 & 1.000 \\
\hline Real Sociedad & 1.311 & 1.000 & 1.568 & 1.113 & 1.146 & 1.011 & 1.023 & 1.090 \\
\hline Betis & 1.277 & 1.011 & 1.361 & 1.335 & 1.282 & 1.010 & 1.066 & 1.239 \\
\hline Getafe & 1.294 & 1.136 & 1.890 & 1.083 & 1.325 & 1.014 & 1.247 & 1.277 \\
\hline Espanyol & 1.224 & 1.114 & 1.476 & 1.000 & 1.248 & 1.011 & 1.186 & 1.257 \\
\hline Rayo Vallecano & 1.164 & 1.074 & 1.480 & 1.650 & 1.303 & 1.011 & 1.285 & 1.000 \\
\hline Zaragoza & 1.147 & 1.068 & 1.595 & 2.139 & 1.278 & 1.014 & 1.146 & 1.083 \\
\hline Granada C.F & 1.188 & 1.009 & 1.438 & 1.926 & 1.236 & 1.031 & 1.217 & 1.217 \\
\hline Villarreal & 1.400 & 1.024 & 1.665 & 2.099 & 1.293 & 1.018 & 1.069 & 1.232 \\
\hline Sporting de Gijón & 1.159 & 1.027 & 1.642 & 1.348 & 1.465 & 1.017 & 1.143 & 1.145 \\
\hline Racing Santander & 1.305 & 1.104 & 2.071 & 2.017 & 1.361 & 1.000 & 1.097 & 1.055 \\
\hline
\end{tabular}


Table 4.- Efficiency results for the 2012-2013 season

\begin{tabular}{|c|c|c|c|c|c|c|c|c|}
\hline \multirow{2}{*}{ Teams } & \multicolumn{4}{|c|}{ Possession (to score a goal) } & \multirow{2}{*}{\begin{tabular}{|c|}
$\begin{array}{c}\text { Possession } \\
\text { (not to lose } \\
\text { the ball) }\end{array}$ \\
$\begin{array}{c}\text { Subdivision } \\
5\end{array}$ \\
\end{tabular}} & \multicolumn{2}{|c|}{ Non possession } & \multirow{2}{*}{\begin{tabular}{|c} 
Goalkeeper's \\
actions \\
Subdivision \\
$\mathbf{8}$ \\
\end{tabular}} \\
\hline & $\begin{array}{c}\text { Subdivision } \\
1\end{array}$ & $\begin{array}{c}\text { Subdivision } \\
2\end{array}$ & $\begin{array}{c}\text { Subdivision } \\
3 \\
\end{array}$ & $\begin{array}{c}\text { Subdivision } \\
4\end{array}$ & & \begin{tabular}{|c|} 
Subdivision \\
6
\end{tabular} & $\begin{array}{c}\text { Subdivision } \\
7\end{array}$ & \\
\hline Barcelona & 2.052 & 1.074 & 1.000 & 1.000 & 1.075 & 1.000 & 1.000 & 1.000 \\
\hline Real Madrid & 1.000 & 1.000 & 1.000 & 1.484 & 1.000 & 1.024 & 1.071 & 1.088 \\
\hline At. Madrid & 1.154 & 1.167 & 1.287 & 1.688 & 1.393 & 1.000 & 1.135 & 1.216 \\
\hline Real Sociedad & 1.244 & 1.070 & 1.349 & 1.737 & 1.100 & 1.018 & 1.039 & 1.000 \\
\hline Valencia & 1.166 & 1.058 & 1.180 & 1.827 & 1.154 & 1.008 & 1.084 & 1.197 \\
\hline Málaga & 1.559 & 1.102 & 1.613 & 1.810 & 1.366 & 1.034 & 1.166 & 1.120 \\
\hline Betis & 1.346 & 1.001 & 1.483 & 1.627 & 1.216 & 1.022 & 1.026 & 1.159 \\
\hline Rayo Vallecano & 1.261 & 1.036 & 1.260 & 2.467 & 1.323 & 1.032 & 1.328 & 1.132 \\
\hline Sevilla & 1.136 & 1.102 & 1.199 & 2.066 & 1.142 & 1.009 & 1.156 & 1.123 \\
\hline Getafe & 1.186 & 1.055 & 1.401 & 2.169 & 1.304 & 1.010 & 1.131 & 1.106 \\
\hline Levante & 1.233 & 1.024 & 1.538 & 2.169 & 1.531 & 1.004 & 1.043 & 1.000 \\
\hline Athletic Club & 1.376 & 1.156 & 1.447 & 1.198 & 1.250 & 1.006 & 1.116 & 1.000 \\
\hline Espanyol & 1.374 & 1.097 & 1.884 & 2.068 & 1.353 & 1.009 & 1.090 & 1.191 \\
\hline Valladolid & 1.764 & 1.066 & 1.332 & 1.717 & 1.000 & 1.011 & 1.080 & 1.080 \\
\hline Granada CF & 1.286 & 1.000 & 1.303 & 2.717 & 1.637 & 1.016 & 1.264 & 1.182 \\
\hline Osasuna & 1.146 & 1.097 & 1.284 & 1.000 & 1.188 & 1.020 & 1.164 & 1.237 \\
\hline Celta de Vigo & 1.437 & 1.069 & 1.387 & 1.955 & 1.172 & 1.000 & 1.127 & 1.090 \\
\hline Mallorca & 1.147 & 1.064 & 1.207 & 1.700 & 1.271 & 1.000 & 1.117 & 1.110 \\
\hline Dep. La Coruña & 1.214 & 1.053 & 1.326 & 2.428 & 1.334 & 1.016 & 1.028 & 1.128 \\
\hline Zaragoza & 1.280 & 1.000 & 1.586 & 2.670 & 1.242 & 1.002 & 1.196 & 1.000 \\
\hline
\end{tabular}


Table 5.- Efficiency results for the 2013-2014 season

\begin{tabular}{|c|c|c|c|c|c|c|c|c|}
\hline \multirow{2}{*}{ Teams } & \multicolumn{4}{|c|}{ Possession (to score a goal) } & \multirow{2}{*}{$\begin{array}{c}\text { Possession } \\
\text { (not to lose } \\
\text { the ball) }\end{array}$} & \multicolumn{2}{|c|}{ Non possession } & \multirow{2}{*}{$\begin{array}{c}\text { Goalkeeper's } \\
\text { actions }\end{array}$} \\
\hline & $\begin{array}{c}\text { Subdivision } \\
1\end{array}$ & $\begin{array}{c}\text { Subdivision } \\
2 \\
\end{array}$ & $\begin{array}{c}\text { Subdivision } \\
3 \\
\end{array}$ & $\begin{array}{c}\text { Subdivision } \\
4\end{array}$ & & $\begin{array}{c}\text { Subdivision } \\
1\end{array}$ & $\begin{array}{c}\text { Subdivision } \\
2 \\
\end{array}$ & \\
\hline At. Madrid & 1.209 & 1.165 & 1.481 & 1.016 & 1.321 & 1.000 & 1.000 & 1.431 \\
\hline Barcelona & 1.419 & 1.093 & 1.183 & 1.000 & 1.068 & 1.000 & 1.049 & 1.179 \\
\hline Real Madrid & 1.000 & 1.000 & 1.000 & 1.000 & 1.000 & 1.014 & 1.000 & 1.164 \\
\hline Athletic Club & 1.396 & 1.083 & 1.657 & 1.164 & 1.149 & 1.004 & 1.068 & 1.203 \\
\hline Sevilla & 1.210 & 1.115 & 1.442 & 1.091 & 1.249 & 1.009 & 1.062 & 1.253 \\
\hline Villarreal & 1.350 & 1.140 & 1.787 & 1.095 & 1.271 & 1.000 & 1.093 & 1.358 \\
\hline Real Sociedad & 1.199 & 1.097 & 1.568 & 1.000 & 1.086 & 1.004 & 1.199 & 1.181 \\
\hline Valencia & 1.365 & 1.073 & 1.559 & 1.354 & 1.095 & 1.010 & 1.104 & 1.000 \\
\hline Celta de Vigo & 1.348 & 1.070 & 1.421 & 1.339 & 1.290 & 1.021 & 1.165 & 1.113 \\
\hline Levante & 1.350 & 1.000 & 2.249 & 1.600 & 1.182 & 1.002 & 1.095 & 1.087 \\
\hline Málaga & 1.265 & 1.074 & 1.509 & 1.614 & 1.262 & 1.025 & 1.222 & 1.096 \\
\hline Rayo Vallecano & 1.444 & 1.025 & 1.501 & 1.756 & 1.137 & 1.017 & 1.212 & 1.436 \\
\hline Espanyol & 1.316 & 1.086 & 1.716 & 1.516 & 1.513 & 1.000 & 1.168 & 1.389 \\
\hline Getafe & 1.419 & 1.003 & 1.867 & 1.691 & 1.329 & 1.000 & 1.162 & 1.135 \\
\hline Granada CF & 1.592 & 1.000 & 1.710 & 2.004 & 1.727 & 1.011 & 1.209 & 1.086 \\
\hline Elche & 1.497 & 1.080 & 1.899 & 2.024 & 1.144 & 1.014 & 1.223 & 1.392 \\
\hline Almería & 1.363 & 1.101 & 1.724 & 1.421 & 1.255 & 1.000 & 1.274 & 1.091 \\
\hline Osasuna & 1.359 & 1.091 & 1.619 & $*$ & 1.000 & 1.011 & 1.143 & 1.318 \\
\hline Valladolid & 1.613 & 1.172 & 1.755 & 1.287 & 1.007 & 1.012 & 1.124 & 1.000 \\
\hline Betis & 1.161 & 1.122 & 1.470 & 1.932 & 1.192 & 1.025 & 1.152 & 1.293 \\
\hline
\end{tabular}

*: As one of its resources has a zero value, it has not been possible to calculate its efficiency ratio 
Table 6.- Efficiency results for the 2014-2015 season

\begin{tabular}{|c|c|c|c|c|c|c|c|c|}
\hline \multirow{2}{*}{ Teams } & \multicolumn{4}{|c|}{ Possession (to score a goal) } & \multirow{2}{*}{$\begin{array}{c}\text { Possession } \\
\text { (not to lose } \\
\text { the ball) }\end{array}$} & \multicolumn{2}{|c|}{ Non possession } & \multirow{2}{*}{\begin{tabular}{|c|}
$\begin{array}{c}\text { Goalkeeper's } \\
\text { actions }\end{array}$ \\
$\begin{array}{c}\text { Subdivision } \\
3\end{array}$ \\
\end{tabular}} \\
\hline & $\begin{array}{c}\text { Subdivision } \\
1\end{array}$ & \begin{tabular}{|c} 
Subdivision \\
2
\end{tabular} & \begin{tabular}{|c} 
Subdivision \\
3 \\
\end{tabular} & \begin{tabular}{|c} 
Subdivision \\
4
\end{tabular} & & \begin{tabular}{|c|} 
Subdivision \\
1
\end{tabular} & $\begin{array}{c}\text { Subdivision } \\
2\end{array}$ & \\
\hline Barcelona & 1.443 & 1.022 & 1.105 & 1.000 & 1.000 & 1.000 & 1.000 & 1.015 \\
\hline Real Madrid & 1.000 & 1.000 & 1.000 & 1.022 & 1.000 & 1.025 & 1.126 & 1.011 \\
\hline At. Madrid & 1.271 & 1.121 & 1.555 & 1.158 & 1.065 & 1.007 & 1.000 & 1.387 \\
\hline Valencia & 1.259 & 1.018 & 1.743 & 1.111 & 1.245 & 1.018 & 1.156 & 1.000 \\
\hline Sevilla & 1.237 & 1.097 & 1.416 & 1.138 & 1.123 & 1.008 & 1.136 & 1.245 \\
\hline Villarreal & 1.134 & 1.103 & 1.160 & 1.000 & 1.000 & 1.017 & 1.167 & 1.416 \\
\hline Athletic Club & 1.424 & 1.134 & 1.497 & 1.822 & 1.160 & 1.016 & 1.253 & 1.011 \\
\hline Celta de Vigo & 1.310 & 1.181 & 1.283 & 1.843 & 1.217 & 1.000 & 1.115 & 1.052 \\
\hline Málaga & 1.230 & 1.083 & 1.452 & 1.911 & 1.276 & 1.020 & 1.307 & 1.114 \\
\hline Espanyol & 1.425 & 1.092 & 1.847 & 1.358 & 1.399 & 1.008 & 1.289 & 1.097 \\
\hline Rayo Vallecano & 1.400 & 1.026 & 1.439 & 1.263 & 1.109 & 1.020 & 1.371 & 1.134 \\
\hline Real Sociedad & 1.384 & 1.097 & 1.639 & 1.261 & 1.095 & 1.014 & 1.325 & 1.069 \\
\hline Elche & 1.426 & 1.000 & 1.430 & 2.100 & 1.145 & 1.020 & 1.283 & 1.000 \\
\hline Getafe & 1.427 & 1.000 & 1.459 & 1.329 & 1.400 & 1.000 & 1.306 & 1.223 \\
\hline Levante & 1.311 & 1.065 & 1.514 & 1.909 & 1.208 & 1.031 & 1.348 & 1.040 \\
\hline Eibar & 1.416 & 1.069 & 1.533 & 1.187 & 1.195 & 1.008 & 1.287 & 1.198 \\
\hline Dep. La Coruña & 1.489 & 1.036 & 1.620 & 2.024 & 1.228 & 1.021 & 1.306 & 1.178 \\
\hline Granada CF & 1.439 & 1.000 & 1.566 & 2.376 & 1.467 & 1.019 & 1.428 & 1.244 \\
\hline Almería & 1.253 & 1.056 & 1.653 & 1.999 & 1.362 & 1.020 & 1.333 & 1.096 \\
\hline Córdoba & 1.375 & 1.062 & 1.688 & 2.429 & 1.375 & 1.005 & 1.213 & 1.010 \\
\hline
\end{tabular}


Table 7.- Efficiency results for the 2015-2016 season

\begin{tabular}{|c|c|c|c|c|c|c|c|c|}
\hline \multirow{2}{*}{ Teams } & \multicolumn{4}{|c|}{ Possession (to score a goal) } & \multirow{2}{*}{$\begin{array}{l}\text { Possession } \\
\text { (not to lose } \\
\text { the ball) }\end{array}$} & \multicolumn{2}{|c|}{ Non possession } & \multirow{2}{*}{\begin{tabular}{|c|}
$\begin{array}{c}\text { Goalkeeper's } \\
\text { actions }\end{array}$ \\
Subdivision \\
3 \\
\end{tabular}} \\
\hline & $\begin{array}{c}\text { Subdivision } \\
1\end{array}$ & \begin{tabular}{|c|} 
Subdivision \\
2
\end{tabular} & \begin{tabular}{|c|} 
Subdivision \\
3
\end{tabular} & \begin{tabular}{|c|} 
Subdivision \\
4
\end{tabular} & & $\begin{array}{c}\text { Subdivision } \\
1\end{array}$ & \begin{tabular}{|c|} 
Subdivision \\
2
\end{tabular} & \\
\hline Barcelona & 1.403 & 1.063 & 1.105 & 1.000 & 1.049 & 1.006 & 1.047 & 1.000 \\
\hline Real Madrid & 1.000 & 1.052 & 1.000 & 1.000 & 1.000 & 1.000 & 1.000 & 1.000 \\
\hline Atlético de Madrid & 1.233 & 1.185 & 1.332 & 1.000 & 1.320 & 1.000 & 1.000 & 1.219 \\
\hline Villarreal & 1.589 & 1.131 & 1.866 & 1.143 & 1.126 & 1.016 & 1.113 & 1.414 \\
\hline Athletic Club & 1.320 & 1.104 & 1.558 & 1.175 & 1.116 & 1.026 & 1.000 & 1.164 \\
\hline Celta de Vigo & 1.538 & 1.105 & 1.783 & 1.301 & 1.152 & 1.032 & 1.000 & 1.174 \\
\hline Sevilla & 1.142 & 1.203 & 1.608 & 1.416 & 1.141 & 1.030 & 1.195 & 1.232 \\
\hline Málaga CF & 1.148 & 1.184 & 1.561 & 1.692 & 1.179 & 1.033 & 1.103 & 1.359 \\
\hline Real Sociedad & 1.303 & 1.131 & 1.835 & 1.000 & 1.139 & 1.026 & 1.122 & 1.009 \\
\hline Real Betis & 1.398 & 1.110 & 2.115 & 1.692 & 1.437 & 1.014 & 1.214 & 1.109 \\
\hline Valencia & 1.449 & 1.130 & 2.178 & 1.342 & 1.329 & 1.032 & 1.214 & 1.000 \\
\hline UD Las Palmas & 1.600 & 1.072 & 1.977 & 1.426 & 1.104 & 1.034 & 1.129 & 1.126 \\
\hline Eibar & 1.328 & 1.044 & 1.471 & 1.392 & 1.220 & 1.031 & 1.068 & 1.319 \\
\hline Espanyol & 1.458 & 1.034 & 1.877 & 1.360 & 1.378 & 1.025 & 1.085 & 1.137 \\
\hline Dep. La Coruña & 1.218 & 1.133 & 1.375 & $1.000 *$ & 1.000 & 1.039 & 1.037 & 1.059 \\
\hline Granada CF & 1.298 & 1.000 & 1.736 & 1.474 & 1.434 & 1.041 & 1.167 & 1.291 \\
\hline Sporting de Gijón & 1.410 & 1.056 & 1.733 & 1.297 & 1.339 & 1.022 & 1.095 & 1.045 \\
\hline Rayo Vallecano & 1.251 & 1.091 & 1.395 & 1.307 & 1.152 & 1.047 & 1.270 & 1.037 \\
\hline Getafe & 1.233 & 1.078 & 1.478 & 1.549 & 1.522 & 1.043 & 1.256 & 1.272 \\
\hline Levante & 1.256 & 1.069 & 1.657 & 1.546 & 1.406 & 1.027 & 1.230 & 1.248 \\
\hline
\end{tabular}

*: It is not considered efficient because its slacks do not have zero values. 
Table 8.- Efficiency results applying the proposal by Ruggiero (2004)

\begin{tabular}{|c|c|c|c|c|c|c|c|c|}
\hline \multirow{2}{*}{ Teams } & \multicolumn{4}{|c|}{ Possession (to score a goal) } & \multirow{2}{*}{$\begin{array}{c}\text { Possession } \\
\text { (not to lose } \\
\text { the ball) } \\
\begin{array}{c}\text { Subdivision } \\
5\end{array} \\
\end{array}$} & \multicolumn{2}{|c|}{ Non possession } & \multirow{2}{*}{\begin{tabular}{|c} 
Goalkeeper \\
actions
\end{tabular}} \\
\hline & $\begin{array}{c}\text { Subdivision } \\
1\end{array}$ & $\begin{array}{c}\text { Subdivision } \\
2\end{array}$ & $\begin{array}{c}\text { Subdivisión } \\
3\end{array}$ & $\begin{array}{c}\text { Subdividion } \\
4\end{array}$ & & $\begin{array}{c}\text { Subdivision } \\
6\end{array}$ & $\begin{array}{c}\text { Subdivision } \\
7\end{array}$ & \\
\hline Almería & $130.11 \%$ & $118.01 \%$ & $168.06 \%$ & $169.05 \%$ & $134.13 \%$ & $102.82 \%$ & $120.87 \%$ & $108.13 \%$ \\
\hline At. Madrid & $116.57 \%$ & $120.51 \%$ & $137.36 \%$ & $123.30 \%$ & $126.75 \%$ & $100.00 \%$ & $100.00 \%$ & $118.21 \%$ \\
\hline Athletic Club & $139.87 \%$ & $119.22 \%$ & $157.73 \%$ & $111.13 \%$ & $116.33 \%$ & $101.03 \%$ & $109.46 \%$ & $107.02 \%$ \\
\hline Barcelona & $155.45 \%$ & $112.34 \%$ & $120.80 \%$ & $100.00 \%$ & $104.77 \%$ & $100.00 \%$ & $100.00 \%$ & $102.27 \%$ \\
\hline Betis & $122.62 \%$ & $107.54 \%$ & $142.92 \%$ & $123.92 \%$ & $122.58 \%$ & $101.97 \%$ & $107.75 \%$ & $118.91 \%$ \\
\hline Celta de Vigo & $139.33 \%$ & $115.40 \%$ & $144.44 \%$ & $139.17 \%$ & $118.22 \%$ & $100.92 \%$ & $112.21 \%$ & $112.35 \%$ \\
\hline Córdoba & $142.35 \%$ & $117.65 \%$ & $165.51 \%$ & $110.59 \%$ & $129.53 \%$ & $101.04 \%$ & $107.53 \%$ & $125.48 \%$ \\
\hline Dep. La Coruña & $129.39 \%$ & $108.12 \%$ & $146.75 \%$ & $142.54 \%$ & $109.78 \%$ & $102.05 \%$ & $106.17 \%$ & $106.92 \%$ \\
\hline Eibar & $142.13 \%$ & $110.98 \%$ & $189.59 \%$ & $131.50 \%$ & $123.88 \%$ & $101.32 \%$ & $100.00 \%$ & $104.65 \%$ \\
\hline Elche & $145.45 \%$ & $100.00 \%$ & $142.30 \%$ & $110.12 \%$ & $117.59 \%$ & $102.70 \%$ & $105.60 \%$ & $116.73 \%$ \\
\hline Espanyol & $134.71 \%$ & $112.44 \%$ & $163.50 \%$ & $124.00 \%$ & $137.25 \%$ & $100.98 \%$ & $115.52 \%$ & $122.95 \%$ \\
\hline Getafe & $130.08 \%$ & $113.33 \%$ & $166.27 \%$ & $139.15 \%$ & $136.14 \%$ & $101.22 \%$ & $116.68 \%$ & $116.05 \%$ \\
\hline Granada & $134.64 \%$ & $104.87 \%$ & $152.17 \%$ & $182.62 \%$ & $144.67 \%$ & $102.50 \%$ & $122.39 \%$ & $110.65 \%$ \\
\hline Levante & $129.10 \%$ & $106.62 \%$ & $167.60 \%$ & $154.15 \%$ & $137.01 \%$ & $101.91 \%$ & $111.23 \%$ & $104.60 \%$ \\
\hline Málaga & $127.70 \%$ & $115.79 \%$ & $155.08 \%$ & $127.09 \%$ & $128.99 \%$ & $101.98 \%$ & $111.81 \%$ & $108.05 \%$ \\
\hline Mallorca & $114.16 \%$ & $117.93 \%$ & $130.92 \%$ & $134.30 \%$ & $120.91 \%$ & $100.00 \%$ & $114.51 \%$ & $108.70 \%$ \\
\hline Osasuna & $120.72 \%$ & $111.20 \%$ & $143.12 \%$ & $100.00 \%$ & $109.61 \%$ & $101.91 \%$ & $113.62 \%$ & $124.93 \%$ \\
\hline Racing Santander & $133.61 \%$ & $121.06 \%$ & $209.89 \%$ & $176.99 \%$ & $136.65 \%$ & $100.36 \%$ & $106.47 \%$ & $100.00 \%$ \\
\hline Rayo Vallecano & $129.94 \%$ & $110.60 \%$ & $140.98 \%$ & $146.47 \%$ & $119.76 \%$ & $102.40 \%$ & $120.43 \%$ & $111.18 \%$ \\
\hline Real Betis & $145.44 \%$ & $115.55 \%$ & $197.44 \%$ & $153.74 \%$ & $139.29 \%$ & $100.16 \%$ & $109.79 \%$ & $103.19 \%$ \\
\hline Real Madrid & $100.00 \%$ & $100.00 \%$ & $100.00 \%$ & $100.00 \%$ & $100.00 \%$ & $101.69 \%$ & $100.00 \%$ & $106.72 \%$ \\
\hline Real Sociedad & $127.84 \%$ & $110.94 \%$ & $157.70 \%$ & $100.00 \%$ & $110.69 \%$ & $101.35 \%$ & $110.44 \%$ & $103.28 \%$ \\
\hline Sevilla & $113.32 \%$ & $116.09 \%$ & $136.96 \%$ & $136.43 \%$ & $113.63 \%$ & $101.70 \%$ & $106.63 \%$ & $115.91 \%$ \\
\hline Sporting de Gijón & $131.64 \%$ & $108.11 \%$ & $164.27 \%$ & $110.06 \%$ & $139.82 \%$ & $101.23 \%$ & $105.03 \%$ & $100.79 \%$ \\
\hline UD Las Palmas & $166.48 \%$ & $103.51 \%$ & $184.50 \%$ & $134.72 \%$ & $110.09 \%$ & $101.31 \%$ & $103.24 \%$ & $104.80 \%$ \\
\hline Valencia & $129.17 \%$ & $113.26 \%$ & $155.66 \%$ & $113.83 \%$ & $115.92 \%$ & $101.66 \%$ & $109.78 \%$ & $100.00 \%$ \\
\hline Valladolid & $160.31 \%$ & $120.75 \%$ & $151.04 \%$ & $120.08 \%$ & $100.00 \%$ & $101.52 \%$ & $110.88 \%$ & $100.00 \%$ \\
\hline Villarreal & $136.67 \%$ & $115.54 \%$ & $155.83 \%$ & $129.92 \%$ & $119.52 \%$ & $101.32 \%$ & $106.23 \%$ & $130.82 \%$ \\
\hline Zaragoza & $118.99 \%$ & $104.92 \%$ & $165.38 \%$ & $195.36 \%$ & $125.20 \%$ & $100.71 \%$ & $117.74 \%$ & $109.57 \%$ \\
\hline
\end{tabular}

